\title{
Natural rubber nanocomposites based on hybrid filler of zinc nanoparticles and carbon nanotubes: Electrical conductivity and other related properties
}

\author{
N. Thongkong ${ }^{1}$, S. Wisunthorn ${ }^{1}$, S. Pichaiyut ${ }^{*}$, C. Nakason ${ }^{1}$, S. Kiatkamjornwong ${ }^{2,3}$ \\ ${ }^{1}$ Faculty of Science and Industrial Technology, Prince of Songkla University, 84000 Surat Thani Campus, Thailand \\ ${ }^{2}$ Office of Research Affairs, Chulalongkorn University, Phayathai Road, Wangmai, Pathumwan, 10330 Bangkok, \\ Thailand \\ ${ }^{3}$ FRS(T), Academy of Science, the Office of Royal Society, Sanam Suea Pa, Dusit, 10300 Bangkok, Thailand
}

Received 3 April 2020; accepted in revised form 27 May 2020

\begin{abstract}
Hybrid filler of carbon nanotubes $(\mathrm{CNT})$ and zinc oxide $(\mathrm{ZnO})$ nanoparticles were prepared and then mixed with natural rubber (NR). The ZnO nanoparticles were first synthesized by the sol-gel method. The NR-CNT/ZnO nanocomposites were prepared by latex mixing. Various proportions of $\mathrm{ZnO}$ in the $\mathrm{CNT} / \mathrm{ZnO}$ hybrid filler were tested by mixing with $\mathrm{NR}$ to eventually form NR-CNT/ZnO nanocomposites. It was found that the optimum $\mathrm{ZnO}$ content in $\mathrm{CNT} / \mathrm{ZnO}$ hybrid filler was about $3 \mathrm{phr}$. These $\mathrm{ZnO}$ contents provided the NR hybrid composite with superior mechanical properties in terms of tensile strength and modulus, together with good electrical conductivity and dielectric properties. In addition, stress relaxation tests revealed stronger filler network formation after incorporation of CNT-ZnO hybrid filler into the NR matrix. It might be due to electrostatic interactions between $\mathrm{CNT}$ and $\mathrm{ZnO}$, also contributing to high electrical conductivity and dielectric properties of the NR-CNT/ZnO composites, when compared to a solely CNT filled NR composite. Furthermore, the Payne effect and morphological properties were qualitatively analyzed, indicating that CNT dispersion was finer in the NR-CNT/ZnO composites having about 1 to $3 \mathrm{phr} \mathrm{ZnO}$ content in $\mathrm{CNT} / \mathrm{ZnO}$. Higher contents of $\mathrm{ZnO}$ in $\mathrm{CNT} / \mathrm{ZnO}$ hybrid filler caused large filler aggregates degrading mechanical and electrical properties.
\end{abstract}

Keywords: nanocomposites, natural rubber, carbon nanotube, zinc oxide nanoparticles, hybrid filler

\section{Introduction}

Conductive rubber composites have been widely investigated by incorporating electrically conductive fillers into the insulating rubber matrix. In recent years, a great deal of attention has been paid to a new type of carbon nanofiller, the carbon nanotubes (CNT). It has been well established that a CNT consists of rolled-up graphite sheets built from $\mathrm{sp}^{2}$ carbon units. That is, a carbon atom in a CNT structure contains one valence electron, which is capable of moving around the CNT surfaces. This definitely enhances both thermal and electrical conductivities [1]. Therefore, CNT has been extensively studied in rubber nanocomposites due to their unique structure and properties [2]. Incorporating CNT can cause dramatic changes owing to their ability to form three-dimensional interconnected networks at very low loadings. The high aspect ratio and large specific surface area of CNT facilitate interfacial interactions with the rubber matrix, complementing the remarkable structural, mechanical, and electrical properties [3]. Typically, CNT fillers could transform natural rubber 
(NR) from an electrical insulator to a conductive material with outstanding flexibility, elasticity, and mechanical properties [4].

However, agglomeration of CNT normal in the rubber matrix due to interactions of polar functional groups on CNT surfaces via hydrogen bonds and Van der Waals attraction. It makes it more difficult for CNT networks or conductive paths to form in the insulating rubber matrix, and even the paths formed require electron tunneling between the conductive particles [1]. The agglomeration of CNT may also cause inferior electrical conductivity and mechanical properties of the NR/CNT nanocomposites [5]. This major drawback is still a challenge for developing a new generation of NR/CNT composites. Generally, the main route to improve the dispersion of CNT in the rubber matrix is by reducing their hydrogen bonding and Van der Waals interactions, thereby reducing the agglomeration tendency. Also, surface treatment of CNT to either reducing H-bond or polarity of CNT has been performed [6].

The CNT loadings and its agglomeration play an important role in the properties of NR nanocomposites. It was found that the optimum CNT loading in NR/ CNT nanocomposite was about 3 phr [6]. Higher CNT loading caused the formation of CNT agglomerate in NR matrix that caused deterioration of mechanical properties due to the failure points at the CNT agglomeration locations. Therefore, to enhance the electrical conductivity of the NR/CNT nanocomposites, several approaches have been exploited to improve the CNT dispersion in a natural rubber matrix [5]. One prominent attempt was by adding secondary fillers into the composites, generating a new conductive hybrid filler [7]. For instance, secondary fillers are used together with CNT for synergy in reinforcing the NR matrix, such as carbon black (CB) [7, 8], ionic liquid (IL) [5], or silver nanoparticles (AgNP) [9].

Zinc oxide $(\mathrm{ZnO})$ nanoparticles are a kind of inorganic multifunctional filler, which has been extensively used as an additive in rubber compounding [10]. It is noted that the $\mathrm{ZnO}$ is a semi-conductive material with remarkable physical and chemical properties, including low toxicity, low cost, high optical activity and stability, high sensitivity to ultraviolet and visible light, together with high thermal and mechanical stability at room temperature $[11,12]$. These properties reveal that $\mathrm{ZnO}$ is a useful material in electronics, optics, photonics, room temperature UV lasers, light-emitting diodes, and sensors [13]. Also, it is applicable in photocatalytic degradation of organic pollutants under ultraviolet-visible light [14]. Some studies have decorated CNT surfaces with $\mathrm{ZnO}$ nanoparticles, with the main aim of promoting CNT network formation. It was found that the $\mathrm{ZnO} / \mathrm{CNT}$ hybrid filler exhibited synergy in photo-inactivation of bacteria [15]. Also, the $\mathrm{ZnO} / \mathrm{CNT}$ hybrid filler had enhanced recyclability and improved rate capability as anode for lithiumion batteries (LIBs) [16]. Moreover, the $\mathrm{ZnO} /$ MWCNT (Multi-walled carbon nanotubes) hybrid filler has also been used for enhancing various properties of polypropylene nanocomposites [17]. It was found that the $\mathrm{ZnO} / \mathrm{MWCNT} / \mathrm{PP}$ nanocomposite films showed improved thermal stability, antibacterial, and antifungal properties, fire resistance, and lower combustion toxicity than the neat PP film [17]. In the present work, the NR-CNT/ZnO nanocomposites were prepared via a latex mixing method. The main aim was to gain a fine dispersion of the CNT/ $\mathrm{ZnO}$ hybrid filler in the NR matrix for superior mechanical properties and electrical conductivity. Effects of loading level of $\mathrm{ZnO}$ in $\mathrm{CNT} / \mathrm{ZnO}$ hybrid filler on properties of NR-CNT/ZnO nanocomposite were also investigated relative to NR composites filled with solely CNT (NR-CNT composites). The electrical properties, relaxation behavior, bound rubber content, and morphological properties were carefully examined.

\section{Experimental}

\subsection{Materials}

High ammonium natural rubber latex (HA) with $60 \%$ dry rubber content (DRC) was manufactured by Tha Chang Rubber Co., Ltd (Surat Thani, Thailand). It was used as the rubber matrix. The multiwalled carbon nanotubes (MWCNT), filler grade, NC7000 with $9.5 \mathrm{~nm}$ diameter, $1.5 \mu \mathrm{m}$ length, and $90 \%$ purity, were manufactured by Nanocyl S.A. (Sambreville, Belgium). The zinc acetate with $99 \%$ purity, the density of $1.94 \mathrm{~g} / \mathrm{cm}^{3}$, and molecular weight of $219.49 \mathrm{~g} / \mathrm{mol}$ was manufactured by Ajax (Sydney, Australia). The curing agents, including sulfur (Ajax Chemical Co., Ltd., Sydney, Australia) and the cure accelerator mercaptobenzothiazole (MBT) (Flexsys Inc., Termoli, Italy) were used as received. The other compounding ingredients were cure activator zinc 
oxide (ZnO) (Global Chemical Co. Ltd., Samut Prakarn, Thailand) and stearic acid (Imperial Chemical Co. Ltd., Pathum Thani, Thailand).

\subsection{Synthesis of $\mathrm{ZnO}$ nanoparticles $(\mathrm{ZnO})$ and the $\mathrm{CNT} / \mathrm{ZnO}$ hybrid filler}

The decoration of $\mathrm{ZnO}$ on the CNT surfaces was first performed by the sol-gel process [18]. First, $1.0 \mathrm{~g}$ of zinc acetate was dissolved in $5 \mathrm{ml}$ deionized water and $125 \mathrm{ml}$ diethylene glycol. Then, the solution was continuously stirred at $180^{\circ} \mathrm{C}$ for $30 \mathrm{~min}$. The solution was then conditioned at room temperature for about $5 \mathrm{~h}$ to provide enough time for the formation of $\mathrm{ZnO}$ sol. A fixed amount of CNT, about $0.2 \mathrm{~g}$, was then added into the $\mathrm{ZnO}$ sol, and it was then sonicated for $1 \mathrm{~h}$ for thorough dispersion of the CNT particles. Afterward, the mixture was cooled to room temperature and then centrifuged. After removal of the liquid phase, the product was thoroughly washed with deionized water and then with ethanol several times.

In this work, the NR-CNT/ZnO nanocomposite was prepared by a latex mixing method. Therefore, an aqueous dispersion of the hybrid filler is needed, and the $\mathrm{CNT} / \mathrm{ZnO}$ hybrid filler in $0.5 \mathrm{wt} \%$ sodium dodecyl sulfate (SDS) surfactant was dispersed in water. The CNT/ZnO dispersion was thoroughly mixed with sonication (OMNI Ruptor 4000, Georgia, USA) for about $10 \mathrm{~min}$ at room temperature. The $\mathrm{pH}$ of the dispersion was then adjusted to 11 , with $3 \mathrm{wt} \%$ sodium hydroxide solution. In this work, the quantity of CNT was fixed at $3 \mathrm{phr}$ because it was the percolation threshold concentration of NR filled CNT [6], but the content of $\mathrm{ZnO}$ was varied at 1, 3, 5 or $7 \mathrm{phr}$. The CNT/ZnO hybrid filler dispersions with various contents of $\mathrm{ZnO}$ were then added into the NR latex (10\% DRC) with continuous mechanical stirring at a rotor speed of $300 \mathrm{rpm}$ for about $30 \mathrm{~min}$. The latex mixture was then cast to glass molds and eventually dried in a hot air oven at $60^{\circ} \mathrm{C}$ for $24 \mathrm{~h}$ to obtain the NR-CNT/ZnO nanocomposite films.

\subsection{Compounding of NR-CNT/ZnO nanocomposites}

The NR-CNT/ZnO compounds were prepared by dry mixing with other chemical ingredients, including stearic acid and zinc oxide activators, MBT accelerator, and sulfur curing agent, per formulation and mixing schedule shown in Table 1 . The mixing was performed in an internal mixer $\left(\right.$ Brabender $^{\mathbb{B}}$ GmbH \& Co. KG, Duisburg, Germany) with a mixing
Table 1. Compounding formulations and mixing schedule for NR-CNT and NR-CNT/ZnO compounds.

\begin{tabular}{|l|c|c|}
\hline \multicolumn{1}{|c|}{ Compound } & $\begin{array}{c}\text { Content } \\
\text { [phr] }\end{array}$ & $\begin{array}{c}\text { Mixing time } \\
{[\text { [min] }}\end{array}$ \\
\cline { 1 - 2 } $\mathrm{NR}$ & 100 & \multirow{2}{*}{7} \\
\cline { 1 - 2 } $\mathrm{CNT}_{3} / \mathrm{ZnO}$ & $0,1,3,5,7$ & \\
\cline { 1 - 2 } Stearic acid & 3 & 1 \\
\cline { 1 - 2 } Zinc oxide $(\mathrm{ZnO})$ & 5 & 1 \\
\hline Mercaptobenzothiazole (MBT) & 0.6 & 1 \\
\hline Sulfur & 2.5 & 2 \\
\hline
\end{tabular}

chamber capacity of $70 \mathrm{~cm}^{3}$ at $60^{\circ} \mathrm{C}$ and a rotor speed of $60 \mathrm{rpm}$ with a total mixing time of $12 \mathrm{~min}$. Besides, cure characteristics of the rubber compounds were analyzed using a moving die rheometer (MDR 2000) (Alpha Technologies, Ohio, USA) at $145^{\circ} \mathrm{C}$. Vulcanized samples were then prepared by compression molding, with model PR1D-W400 L450PM (Charon Tut Co., LTD., Samut Prakarn, Thailand), at $145^{\circ} \mathrm{C}$ using the respective cure time (i.e, $t_{\mathrm{c} 90}$ ) for each sample from the MDR tests. To investigate the influences of $\mathrm{ZnO}$ content in $\mathrm{ZnO} / \mathrm{CNT}$ hybrid filler on properties of NR nanocomposites, the fixed CNT loading at $3 \mathrm{phr}$ was used with various loadings of $\mathrm{ZnO}(1,3,5$, or $7 \mathrm{phr})$ to prepare the NR/CNT-ZnO nanocomposites.

\subsection{Attenuated total reflection Fourier transform infrared spectroscopy (ATR-FTIR)}

Attenuated total reflection Fourier transform infrared spectroscopy (ATR-FTIR), with Perkin-Elmer Spectrometer, Spectrum Two (Perkin Elmer, CA), was used to analyze the gum NR and the NR-CNT/ZnO composite films. The analysis was performed over the wide wavenumber range from 4000 to $400 \mathrm{~cm}^{-1}$ with a resolution of $4 \mathrm{~cm}^{-1}$.

\subsection{X-ray diffraction (XRD)}

The X-ray diffraction (XRD) pattern of the $\mathrm{ZnO}$ nanostructure was recorded with Empyrean X-ray diffractometer (PANalytical B.V., Almelo, The Netherlands) with $\mathrm{Cu}-\mathrm{K} \alpha$ radiation $(k=0.1542 \mathrm{~nm})$.

\subsection{Morphological properties}

Morphological properties of CNT/ZnO hybrid filler were characterized by TEM imaging (Jeol JEM 2010, Jeol Ltd., Tokyo, Japan) with an accelerating voltage of $200 \mathrm{kV}$. The samples were first dispersed in deionized water before spotting on the sample grid for TEM imaging. Furthermore, the morphological 
properties of the NR-CNT/ZnO composites were also characterized by using scanning electron microscopy (SEM) (FEI-Quanta 400, Thermo Fisher Scientific, Brno, Czech Republic) and field emission scanning electron microscopy (FESEM) (Apreo, Thermo Fisher Scientific, Brno, Czech Republic). The samples were first cryogenically fractured in liquid nitrogen to create fresh cross-sectional surfaces. Then, the samples were sputter-coated with a thin layer of gold under vacuum before imaging by SEM or FESEM. In this study, the dispersion of filler in NR-CNT/ZnO composites was characterized by fluorescence stereo microscopy (Leica M205 FCA, Heerbrugg, Switzerland). The samples were initially fast cut with a razor blade in order to create a smooth sample surface for examining.

\subsection{Temperature scanning stress relaxation (TSSR)}

The stress relaxation measurements were performed using a TSSR meter (Brabender ${ }^{\circledR} \mathrm{GmbH} \& \mathrm{Co} . \mathrm{KG}$, Duisburg, Germany). Dumbbell shaped specimens (type 5A, ISO 527). The vulcanized samples were prepared and placed in the sample holder in the test chamber of the TSSR meter. The sample was then conditioned at $23^{\circ} \mathrm{C}$ and $50 \%$ strain for $2 \mathrm{~h}$ to allow the isothermal short-time relaxations [19]. The nonisothermal test was then carried out by increasing test temperature from 23 to $220^{\circ} \mathrm{C}$ at a constant heating rate of $2{ }^{\circ} \mathrm{C} / \mathrm{min}(v)$. The relaxation spectrum $(H(T))$ was automatically calculated based on the relation of relaxation modulus $(E(T))$ and temperature (T) [19] as shown by Equation (1):

$$
H(T)=-T\left[\frac{\mathrm{d} E(T)}{\mathrm{d} T}\right]_{\mathrm{v}=\text { const }}
$$

\subsection{Bound rubber contents}

Bound rubber contents of the NR composites were analyzed by dissolving the soluble parts of the unvulcanized rubber compounds in a solvent. The NR compounds were initially immersed in toluene and conditioned to the equilibrium state for at least $72 \mathrm{~h}$, and the toluene was renewed every $24 \mathrm{~h}$. The samples were later separated from the solvent and then dried at $105^{\circ} \mathrm{C}$ for at least $24 \mathrm{~h}$. In the same manner, the NR compounds were immersed in toluene for at least $72 \mathrm{~h}$ at room temperature either in the normal state or in an ammonia atmosphere with the renewal of toluene every $24 \mathrm{~h}$. Then, the solvent was separated, and the samples were dried at $105^{\circ} \mathrm{C}$ for $24 \mathrm{~h}$ and eventually weighted. It is noted that the ammonia was used to cleave the physical linkages between rubber molecules and filler surfaces. The bound rubber content was then determined as shown by Equations (2) [20]:

Bound rubber content $[\%]=\frac{W_{\mathrm{fg}}-W_{\mathrm{f}}}{W_{\mathrm{p}}}$

where $W_{\mathrm{f}}$ and $W_{\mathrm{p}}$ are the weights of filler and rubber in the specimens, respectively. $W_{\mathrm{fg}}$ is the weight of filler with bound rubber absorbed on it after toluene extraction.

\subsection{Payne effect}

The Payne effect was determined by measuring the storage modulus as a function of strain amplitude with a rubber process analyzer (RPA) (Alpha Technologies, Akron, USA). The Payne effect is typically used to indicate the state of filler dispersion. The test was performed by measuring the storage shear modulus $\left(G^{\prime}\right)$ of each filled un-vulcanized rubber compound under shear deformation with a strain amplitude range of $0.56-100 \%$ at a fixed $1 \mathrm{~Hz}$ oscillation frequency and $100^{\circ} \mathrm{C}$. The Payne effect was quantified by the difference of storage moduli at very low strain $\left(G_{0.56}^{\prime}\right)$ and at very high strain $\left(G^{\prime} 100\right)$.

\subsection{Electrical properties}

Electrical properties of gum and NR-CNT/ZnO vulcanizates were measured at room temperature using an LCR meter (Hioki IM 3533, Hioki E.E. Corporation, Nagano, Japan). A sample with $\sim 2$ mm thickness was first placed between the plates, and then the test was performed over the frequency range from 1 to $10^{5} \mathrm{~Hz}$. The electrical conductivity $(\sigma)$, and dielectric constant $\left(\varepsilon^{\prime}\right)$ were calculated by using Equation (3) and (4), respectively [21]:

$$
\begin{aligned}
\sigma & =\frac{1}{\rho}=\frac{d}{\left(R_{p}\right) A} \\
\varepsilon^{\prime} & =\frac{C_{\mathrm{p}}(A)}{A\left(\varepsilon_{0}\right)}
\end{aligned}
$$

where $d$ and $A$ refer to the sample thickness and the area of an electrode, respectively. The factor $\rho$ is the volume resistivity, the reciprocal of conductivity, and $R_{\mathrm{p}}$ is resistance. The parameter $C_{\mathrm{p}}$ is the parallel capacitance, and $\varepsilon_{0}$ is the dielectric constant of the free space, which is $8.854 \cdot 10^{-12} \mathrm{~F} / \mathrm{m}$. 


\subsection{Dynamic mechanical analysis}

Dynamic mechanical thermal analysis (DMTA) was carried out using Perkin Elmer DMA 8000 (Perkin Elmer Inc., Waltham, USA) in tension mode. The samples were scanned over the temperature range from -100 to $100^{\circ} \mathrm{C}$ with a heating rate of $3{ }^{\circ} \mathrm{C} / \mathrm{min}$ and fixed deformation frequency of $1 \mathrm{~Hz}$.

\subsection{Mechanical properties}

Tensile properties of the gum NR vulcanizate together with NR-CNT/ZnO composites were investigated using a universal tensile testing machine (Tinius Olsen, Co., Ltd., Honey Crock Lane, UK). It is noted that the dumbbell-shaped specimens were prepared from compression-molded sheets. The tests were carried out with an extension rate (or cross-head speed) of $200 \mathrm{~mm} / \mathrm{min}$ at room temperature, according to ISO 37, Type 1A.

\section{Results and discussion}

\subsection{Characterization of $\mathrm{ZnO}$ and $\mathrm{CNT} / \mathrm{ZnO}$ hybrid filler by XRD and TEM}

Figure 1 shows the XRD patterns of $\mathrm{ZnO}$ nanoparticles, CNT and CNT/ZnO hybrid. The XRD peaks for $\mathrm{ZnO}$ nanostructure are seen at $2 \theta=31.73,34.40$, $36.21,47.49,56.52,62.83,66.30,67.87,69.01$, $72.56,76.88$, and $81.36^{\circ}$. These correspond respectively, to (100), (002), (101), (102), (110)), (103), (200), (112), (201), (004), (202) and (104) crystal planes of $\mathrm{ZnO}$ with hexagonal structure [13, 22, 24]. The crystallite size (D) of the $\mathrm{ZnO}$ nanoparticles was then estimated from Scherrer's Equation (5) [23].

$D=\frac{0.9 \lambda}{\beta \cos \theta}$

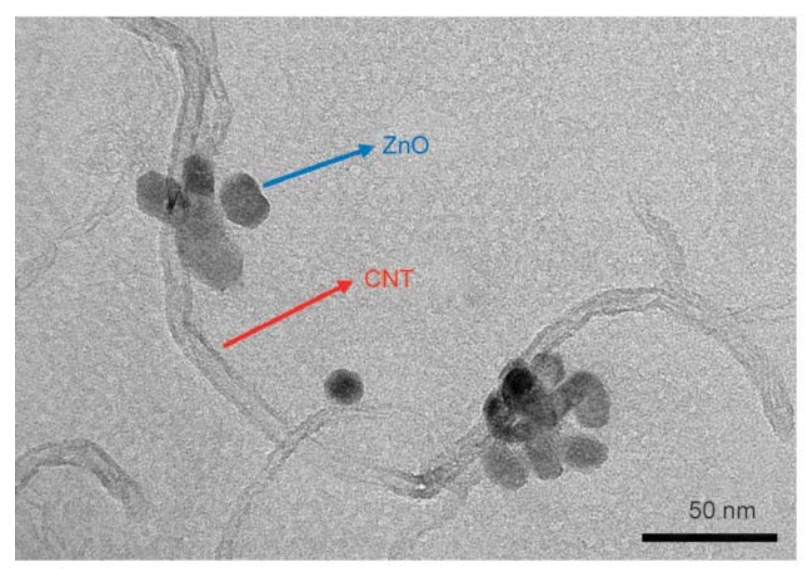

a)

Figure 2. Transmission electron micrographs (TEM) of zinc oxide decorations on CNT surfaces to form CNT/ZnO hybrid nanoparticles at magnifications: (a) $150000 \times$, and (b) $250000 \times$.

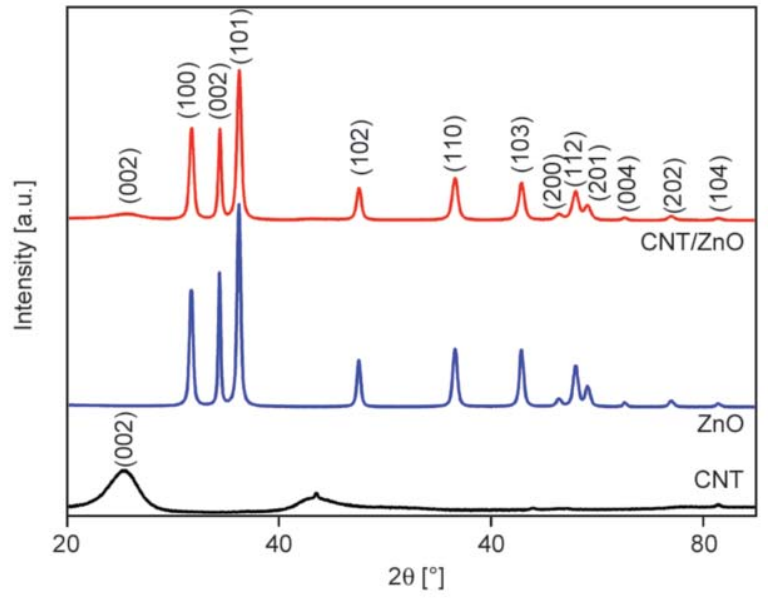

Figure 1. XRD patterns of $\mathrm{ZnO}$ nanoparticles, CNT and $\mathrm{CNT} / \mathrm{ZnO}$ hybrid filler.

where $D$ is the crystallite size, 0.9 is the shape factor, $\lambda$ is the X-ray wavelength, $\beta$ is the full width at half the maximum intensity (FWHM) in radians, and $\theta$ is the Bragg angle.

It was found that the crystallite size $(D)$ of $\mathrm{ZnO}$ nanoparticles calculated based on the maximum peak (101), together with Equation (5), was approximately $8.50 \mathrm{~nm}$. This proves the nano-scale of $\mathrm{ZnO}$ particles. It is also seen in Figure 1, that the XRD pattern for CNT shows a peak at $2 \theta=26^{\circ}$. This relates to the (002) plane in the graphite structure of CNT $[15,24]$. Furthermore, the XRD pattern of the CNT/ $\mathrm{ZnO}$ hybrid composite has a combination of the peaks for CNT and $\mathrm{ZnO}$. The crystallite size $(D)$ of $\mathrm{ZnO}$ nanoparticles decorated on CNT surfaces (i.e., $\mathrm{CNT} / \mathrm{ZnO}$ ) was also calculated based on the maximum peak (101) together with Equation (5) was approximately $5.49 \mathrm{~nm}$.

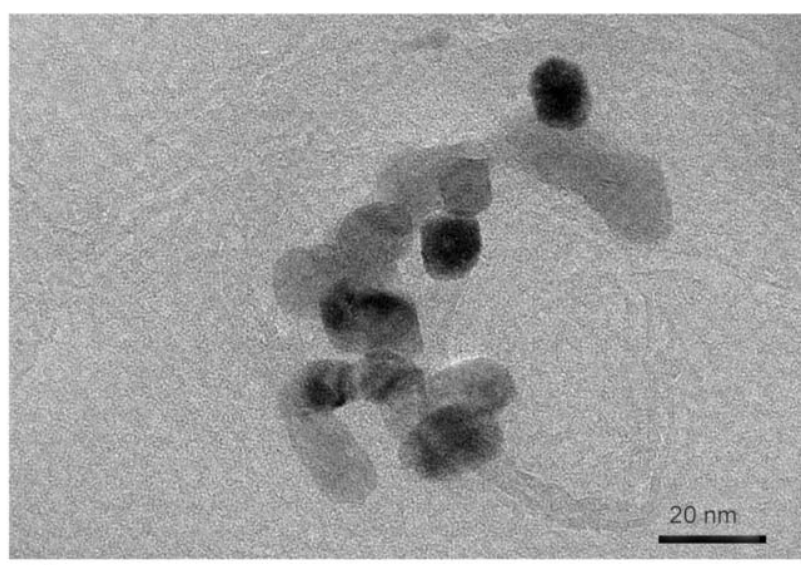

b) 


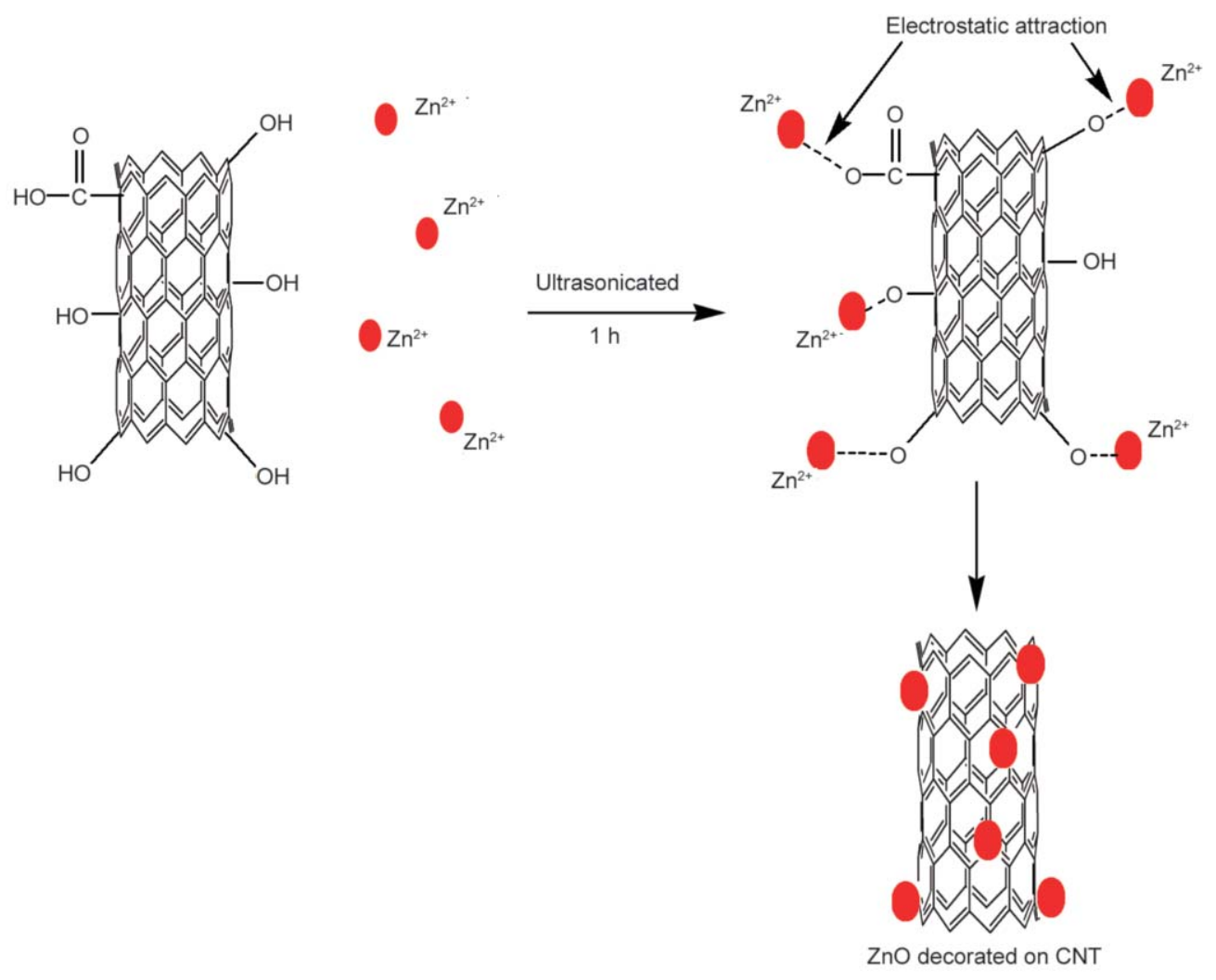

Figure 3. A proposed reaction mechanism for the decoration of CNT bundle surfaces with $\mathrm{ZnO}$ nanoparticles.

Figure 2 shows the TEM micrographs of CNT/ZnO hybrid filler. It is clear that the decoration of $\mathrm{ZnO}$ on CNT surfaces to form the hybrid filler was successful, as clearly seen in Figures 2a and $2 b$. The $\mathrm{ZnO}$ particles adhere to the CNT bundle surfaces. This is clearer in the TEM micrograph of $\mathrm{CNT} / \mathrm{ZnO}$ hybrid filler with the higher 200000 $\times$ magnification (Figure 2b). Therefore, $\mathrm{ZnO}$ nanoparticles and CNT bundle surfaces were clearly in contact. This might be due to interactions between functional groups, i.e., hydroxyl $(-\mathrm{OH})$ and carboxyl groups $(-\mathrm{COOH})$, with negative charges on CNT surfaces and the positive charges of zinc ions $\left(\mathrm{Zn}^{2+}\right)$ in $\mathrm{ZnO}$, as proposed in Figure 3. The $\mathrm{ZnO}$ with a hexagonal structure has an electrical double layer generated by $\mathrm{Zn}^{2+}$ on the surfaces of $\mathrm{ZnO}$ particles [25], while the surfaces of CNT have hydroxyl and carboxyl functional groups with negative charges that are capable of attracting $\mathrm{Zn}^{2+}$ in the $\mathrm{ZnO}$ nanoparticles, together with metal co-ordination linkages [26, 27]. Furthermore, the size of $\mathrm{ZnO}$ nanoparticles estimated from the TEM image in Figure $2 b$ is approximately 8 to $14 \mathrm{~nm}$, which matches well the $8.5 \mathrm{~nm}$ particle size estimated from XRD pattern.

\subsection{ATR-FTIR}

ATR-FTIR spectra of gum NR, NR-CNT ${ }_{3}$, and NR$\mathrm{CNT}_{3} / \mathrm{ZnO}_{3}$ composites are shown in Figure 4. Also, the assignments of the FT-IR absorption peaks are listed in Table 2. The absorption peaks of gum NR are seen at the wavenumbers 1663 and $1546 \mathrm{~cm}^{-1}$, which are assigned to $\mathrm{C}=\mathrm{C}$ stretching and $\mathrm{N}-\mathrm{H}$ bending vibrations of mono-substituted amide II in NR [28], respectively. Additionally, the absorption peak at $841 \mathrm{~cm}^{-1}$ is assigned to $\mathrm{C}-\mathrm{H}$ out-of-plane bending vibrations. Furthermore, the absorption peaks at 1455 and $1375 \mathrm{~cm}^{-1}$ indicate $-\mathrm{C}-\mathrm{H}$ scissoring and $-\mathrm{CH}_{3}$ bending vibrations in NR, respectively. It is also seen in Figure 4 that the FTIR spectrum of NR-CNT 3

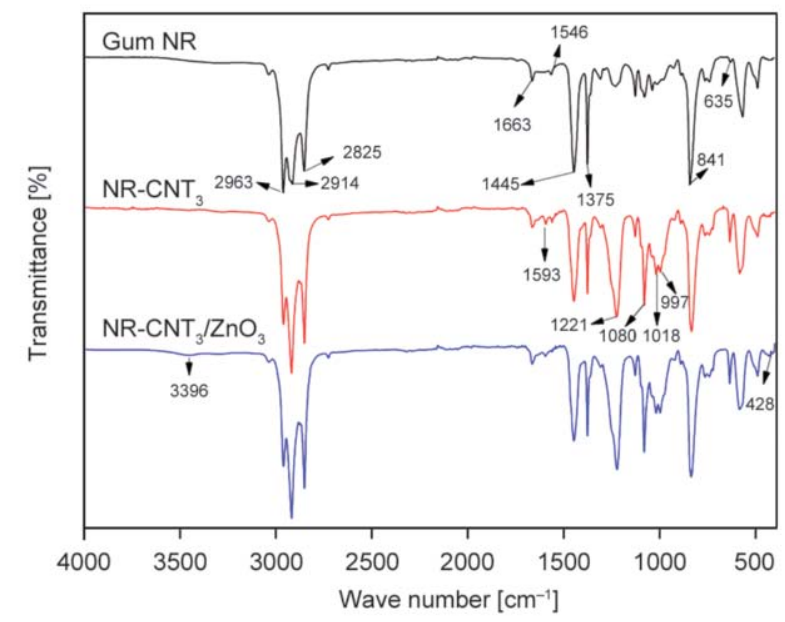

Figure 4. ATR-FTIR spectra of gum NR, and NR-CNT 3 and $\mathrm{NR}-\mathrm{CNT}_{3} / \mathrm{ZnO}_{3}$ composites. 
Table 2. Peak assignments for gum NR, NR-CNT 3 and NR$\mathrm{CNT}_{3} / \mathrm{ZnO}_{3}$ nanocomposite films in the FTIR spectra of Figure 4.

\begin{tabular}{|c|l|}
\hline $\begin{array}{c}\text { Wavenumber } \\
{\left[\mathbf{c m}^{-\mathbf{1}}\right]}\end{array}$ & \multicolumn{1}{c|}{ Assignment } \\
\hline 2963 & $-\mathrm{CH}_{3}$ stretching vibration \\
\hline 2914 & $-\mathrm{CH}_{2}$ stretching vibration \\
\hline 2852 & $-\mathrm{CH}_{2}$ stretching vibration \\
\hline 1663 & $\mathrm{C}=\mathrm{C}$ stretching vibration \\
\hline 1546 & $\mathrm{~N}-\mathrm{H}$ bending vibration of amide \\
\hline 1593 & $\mathrm{C}=\mathrm{O}$ stretching vibration \\
\hline 1445 & $-\mathrm{CH}_{2}$ bending vibration \\
\hline 1375 & $-\mathrm{CH}$ bending vibration \\
\hline 1221 & $\mathrm{C}-\mathrm{O}$ stretching vibration \\
\hline 1080 & $\mathrm{C}-\mathrm{O}$ stretching vibration \\
\hline 1018 & $\mathrm{C}-\mathrm{O}$ stretching vibration \\
\hline 997 & $\mathrm{C}-\mathrm{H}$ out-of-plane bend \\
\hline 841 & $=\mathrm{C}-\mathrm{H}$ out of plane bending \\
\hline 632 & $\mathrm{C}-\mathrm{H}$ bending vibration \\
\hline 428 & $\mathrm{Zn}-\mathrm{O}$ stretching vibration \\
\hline & \\
\hline
\end{tabular}

composite demonstrated a new absorption peak at wavenumber $1593 \mathrm{~cm}^{-1}$, which indicates $\mathrm{C}=\mathrm{O}$ stretching vibrations in CNT $[29,30]$. Additionally, the peak at wavenumber 1018,1080 , and $1221 \mathrm{~cm}^{-1}$ are assigned to $\mathrm{C}-\mathrm{O}$ stretching vibrations [31], which indicates the presence of functional groups on CNT surfaces. Also, FTIR peaks at 1018 and $1221 \mathrm{~cm}^{-1}$ were observed. They are assigned to $\mathrm{C}-\mathrm{N}$ stretching vibrations of functional groups on $\mathrm{CNT}$ surfaces [31]. It is noted that CNT should not have the $\mathrm{C}-\mathrm{N}$ linkages in the structure, but this is possible to be the impurities in the CNT that did not exist in the FTIR spectrum of gum NR in Figure 4.

It is also clearly seen in Figure 4 that the FTIR spectrum of NR-CNT $/ \mathrm{ZnO}_{3}$ film exhibits a new absorption peak at $428 \mathrm{~cm}^{-1}$, which is characteristic of zincoxygen stretching vibrations [13]. Moreover, the peaks at 1658 and $3396 \mathrm{~cm}^{-1}$ are assigned to $\mathrm{O}-\mathrm{H}$ bending and stretching vibrations. The FTIR spectrum of $\mathrm{NR}-\mathrm{CNT}_{3} / \mathrm{ZnO}_{3}$ shows a lower peak intensity of the functional groups on CNT surface at $1593 \mathrm{~cm}^{-1}$. Also, the absorption peaks at 1221,1080 , and $1018 \mathrm{~cm}^{-1}$ in $\mathrm{NR} / \mathrm{CNT}_{3}$ spectrum were slightly shifted to 1218 , 1077 , and $1016 \mathrm{~cm}^{-1}$ in the NR-CNT $3 / \mathrm{ZnO}_{3}$ spectrum, respectively. This might be due to the influence of the hybridization of CNT and $\mathrm{ZnO}$ particles, as indicated in the TEM micrographs (Figure 2) and the proposed reaction mechanisms in Figure 3.

\subsection{Morphological properties}

FESEM and fluorescence stereo-microscopy were used to evaluate the morphological properties of NRCNT and NR-CNT/ZnO composites. Figure 5 shows FESEM micrographs of gum NR, NR-CNT, NR$\mathrm{CNT}_{3} / \mathrm{ZnO}_{3}$, and NR-CNT $/ \mathrm{ZnO}_{5}$ composites. The gum NR (Figure 5a) shows a smooth surface with some small white spots of $\mathrm{ZnO}$. Furthermore, it is clear that NR-CNT composites (Figure $5 \mathrm{~b}$ and $5 \mathrm{e}$ ) had CNT agglomerates. This indicates filler-filler interactions among CNT bundles dominating over fillermatrix interactions between NR and CNT. This may degrade the mechanical strength of NR-CNT composites. However, upon the decoration of CNT surfaces with 3 phr of $\mathrm{ZnO}$, the filler dispersion in NR$\mathrm{CNT}_{3} / \mathrm{ZnO}_{3}$ nanocomposites (Figures $5 \mathrm{c}$ and $5 \mathrm{f}$ ) seems finer than in the NR-CNT composites (Figures $5 \mathrm{~b}$ and $5 \mathrm{e}$ ). This might be attributed to the formation of infinite CNT-ZnO hybrid filler networks in the NR matrix (Figures 2a and 2b). However, large filler agglomerates are seen again upon increasing $\mathrm{ZnO}$ content to $5 \mathrm{phr}$ in the NR-CNT $3 / \mathrm{ZnO}_{5}$ composites (Figures $5 \mathrm{~d}$ and $5 \mathrm{~g}$ ). This confirms that more than $3 \mathrm{phr}$ of $\mathrm{ZnO}$ in the CNT/ZnO hybrid produced larger filler agglomerates. The FESEM micrographs in Figure 5 correlate well to the fluorescence stereo microscopic images, seen in Figure 6. That is, the gum NR vulcanizate showed a large white agglomerate of $\mathrm{ZnO}$ activator (Figure 6a). Also, the NR-CNT composite displayed strong $\mathrm{CNT}$ agglomeration with the agglomerate of $\mathrm{ZnO}$ activator (Figure 6b), whereas the NR-CNT $/ \mathrm{ZnO}_{1}$ (Figure $6 \mathrm{c}$ ) and $\mathrm{NR}-\mathrm{CNT}_{3} /$ $\mathrm{ZnO} 3$ (Figure 6d) composites display better filler dispersion. Furthermore, clearly adding more than $3 \mathrm{phr}$ $\mathrm{ZnO}$ into the $\mathrm{CNT} / \mathrm{ZnO}$ hybrid filler gave larger filler agglomerates shown in Figures 6e and 6f. These characteristics of morphological properties agree with the proposed model in Figure 7. Large CNT agglomerates are formed in the NR-CNT composite because of Van der Waals forces and hydrogen bonding among CNT particles. This typically provides degraded mechanical and other related properties to an NR-CNT composite. However, the NR-CNT/ZnO hybrid composites with the optimum amounts of $\mathrm{ZnO}$ (about 1 and $3 \mathrm{phr}$ ) gave a finer distribution of CNT in the NR matrix. This might be attributed to the hybrid filler connecting to networks in the NR matrix by chemical interactions between the functional groups 


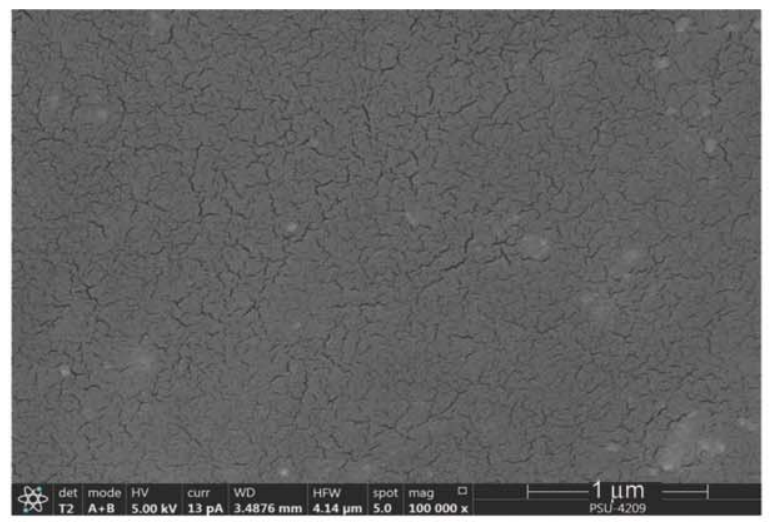

a)
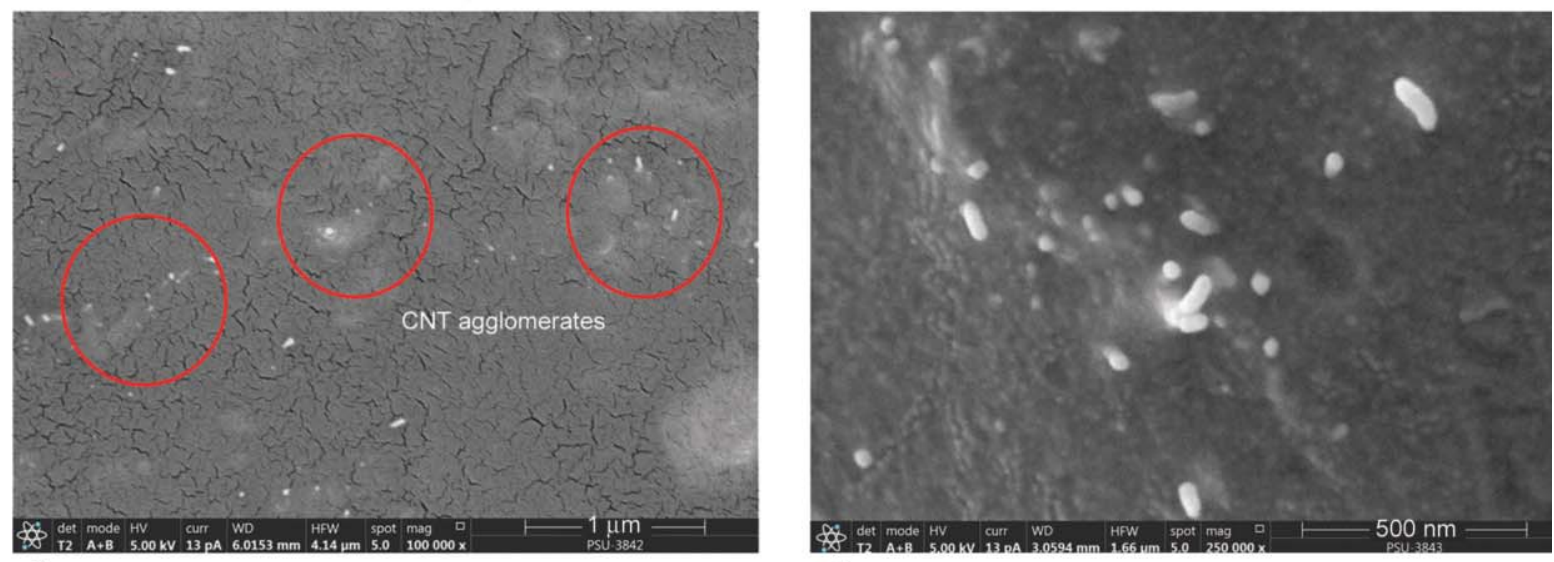

b)

e)
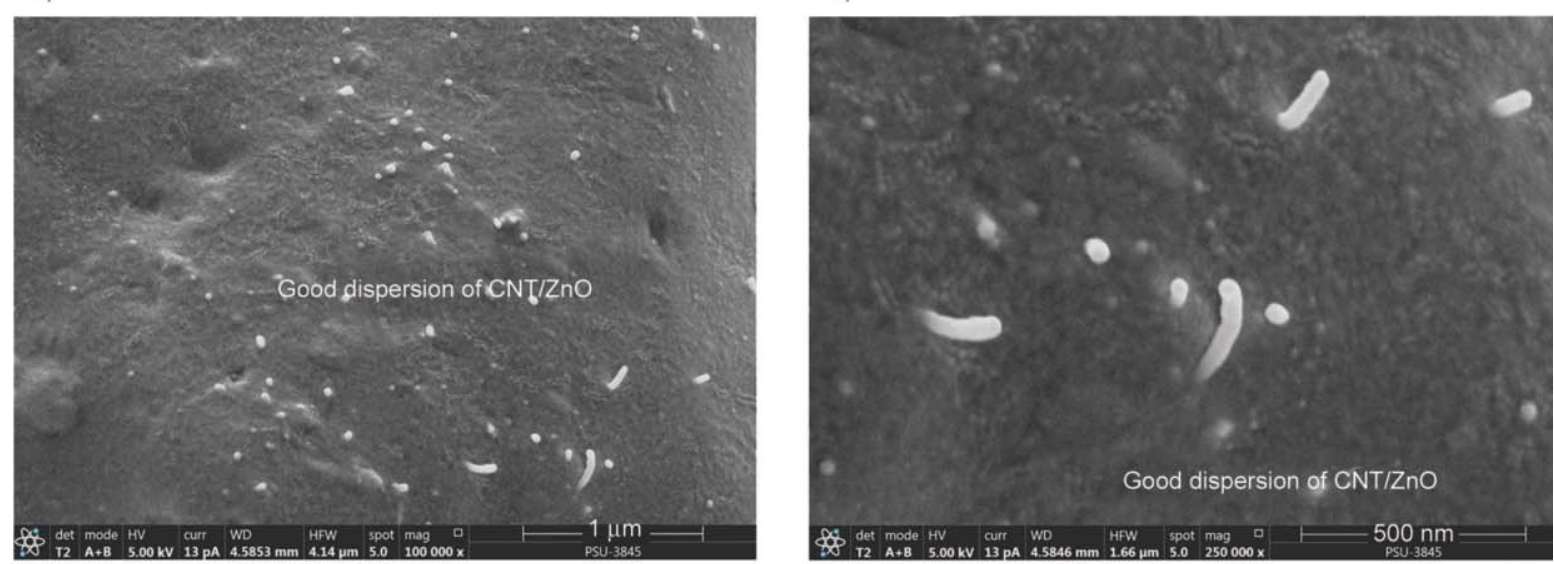

f)
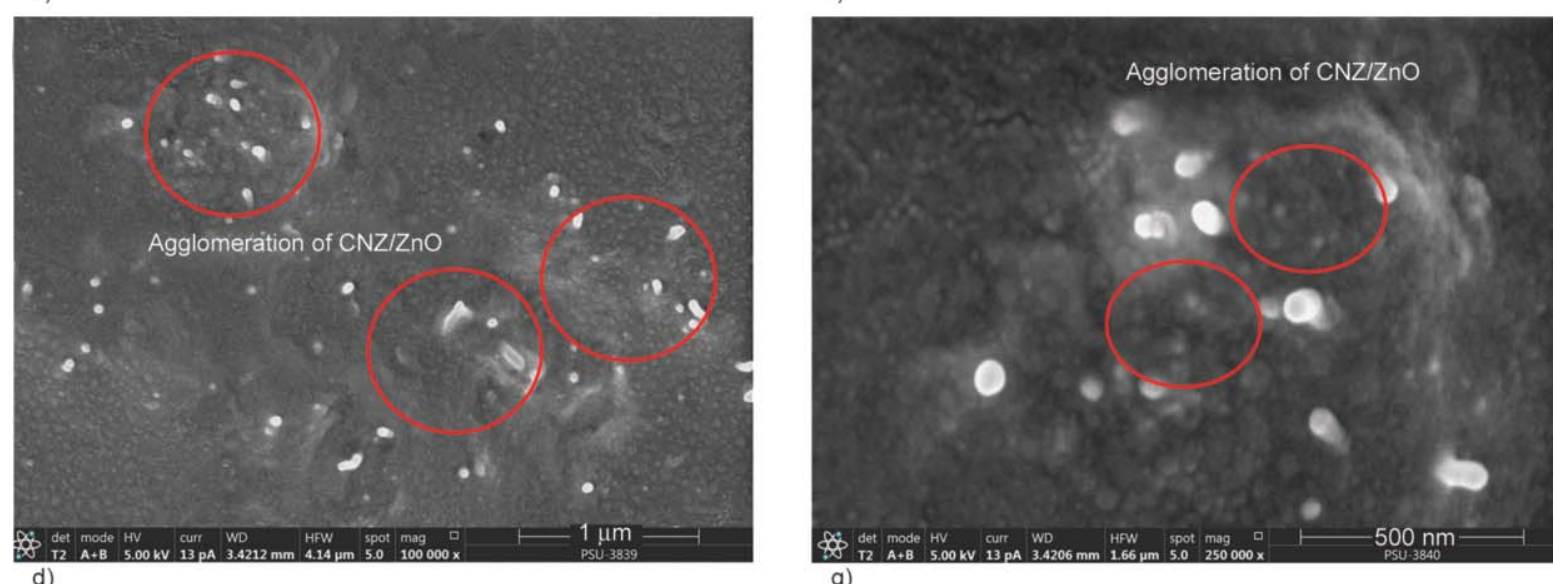

g)

Figure 5. FESEM micrographs of (a) gum NR: $100000 \times$, (b) NR-CNT: $100000 \times$, (c) NR- $\mathrm{CNT}_{3} / \mathrm{ZnO}_{3}: 100000 \times$, (d) NR$\mathrm{CNT}_{3} / \mathrm{ZnO}_{5}: 100000 \times$, (e) NR-CNT: $250000 \times$, (f) NR-CNT $/ \mathrm{ZnO}_{3}: 250000 \times$, and (g) NR-CNT $3 / \mathrm{ZnO}_{5}: 250000 \times$. 
on CNT surfaces with the positively charged zinc ions, as described in Figure 3. In the NR composites with $\mathrm{CNT} / \mathrm{ZnO}$ hybrid filler that has more than $3 \mathrm{phr}$ $\mathrm{ZnO}$ (Figures 6e and 6f), strong agglomeration is

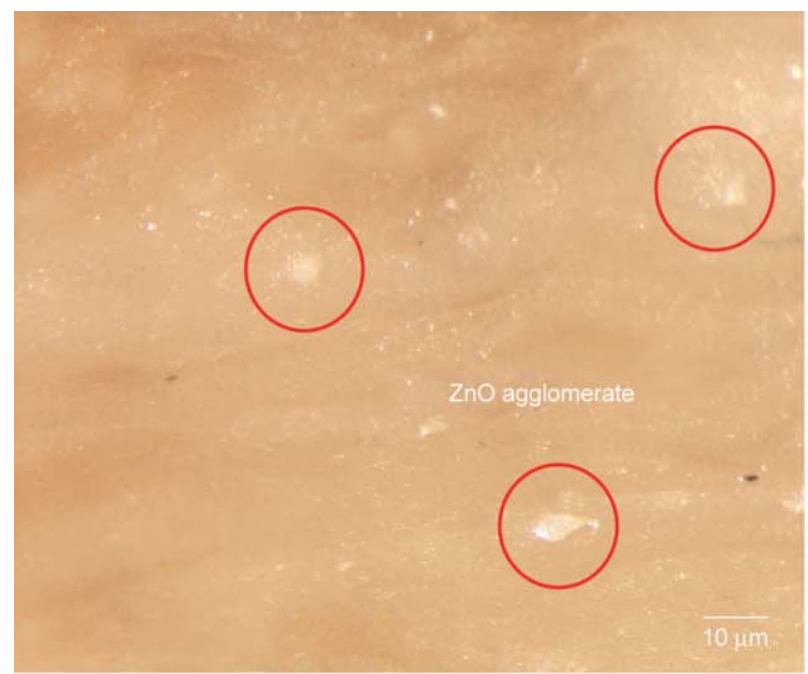

a)

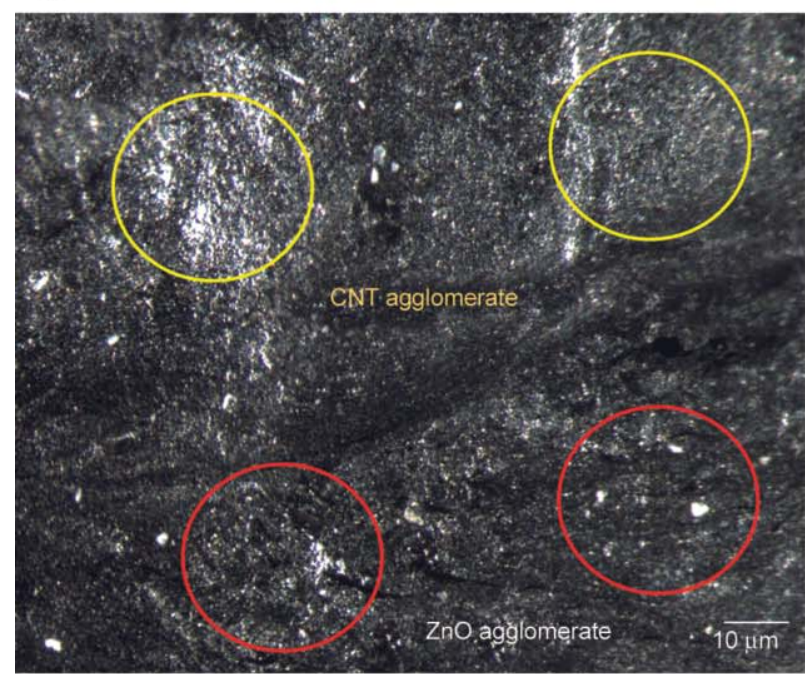

b)

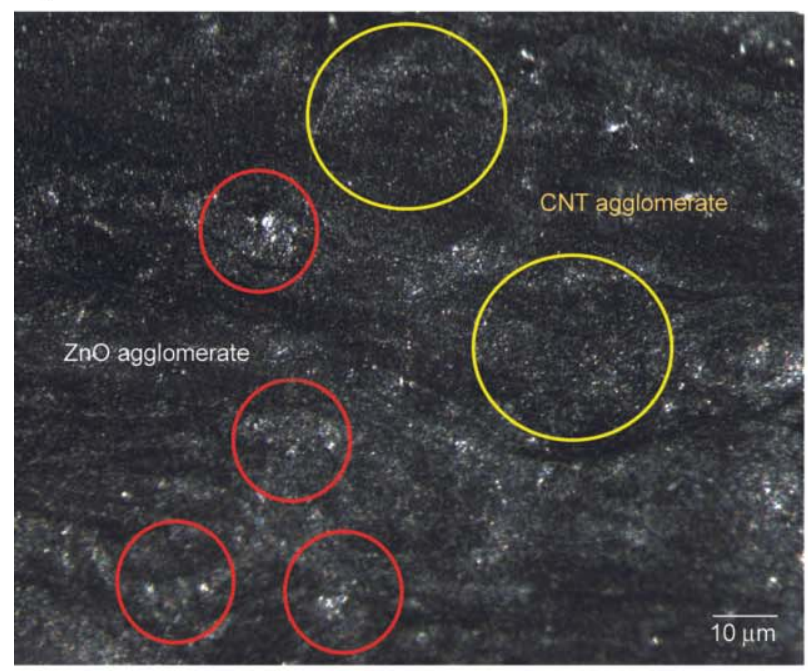

c) clear. This is because the fixed 3 phr of CNT consumes $\mathrm{ZnO}$ to form hybrid filler for about $3 \mathrm{phr}$, while a higher $\mathrm{ZnO}$ loading leaves excess $\mathrm{ZnO}$ in the system. Therefore, the strong and large filler

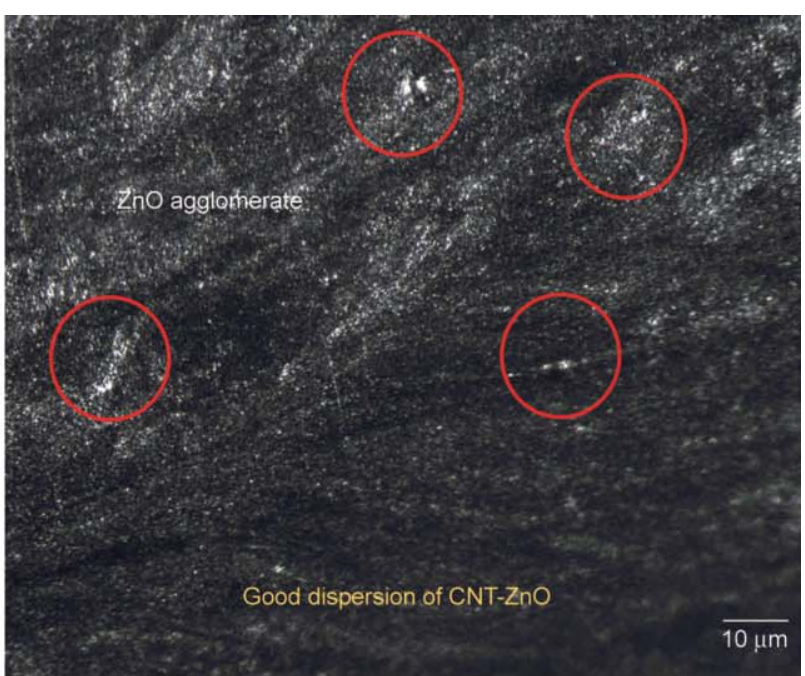

d)

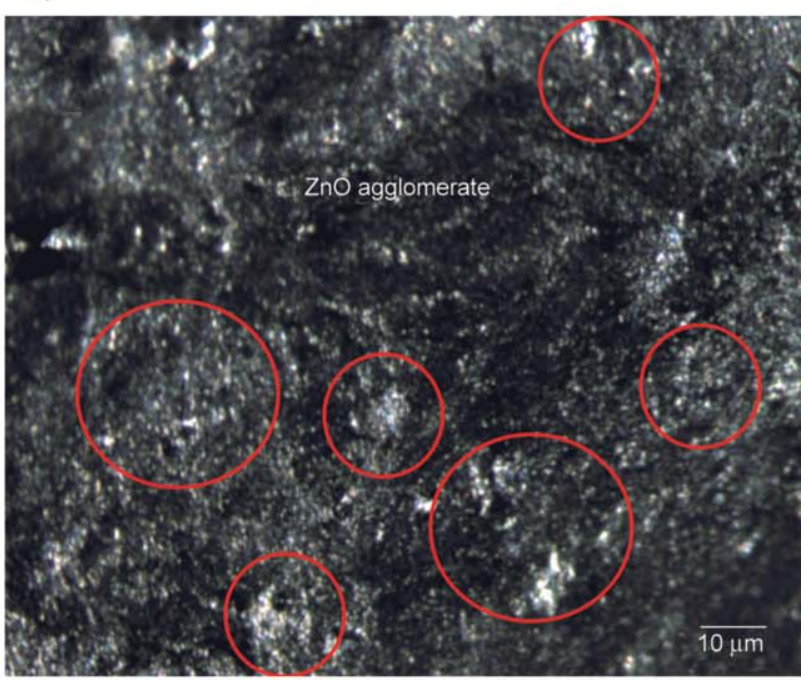

e)

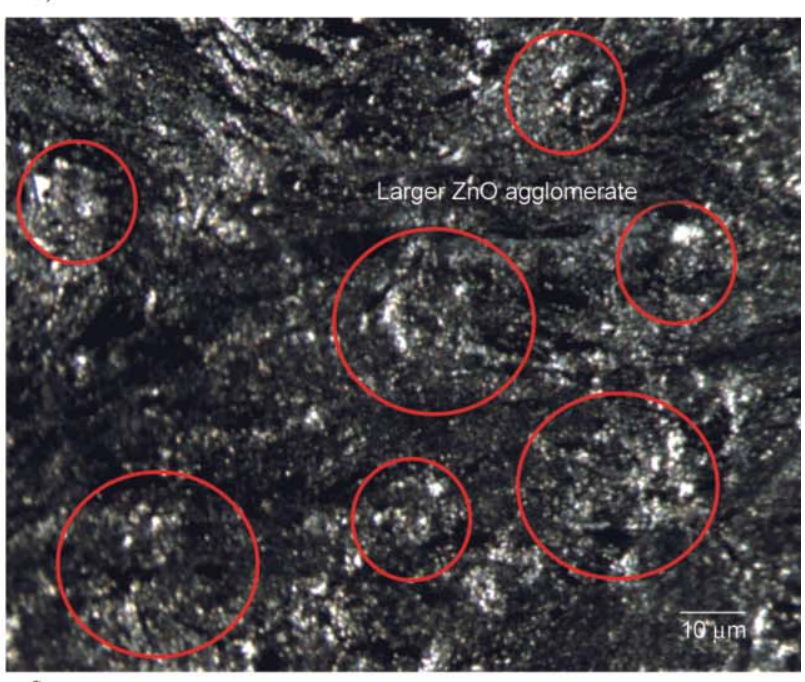

f)

Figure 6. Fluorescence stereo micrographs of (a) gum NR, (b) NR-CNT, (c) NR-CNT $/ \mathrm{ZnO}_{1}$, (d) $\mathrm{NR}-\mathrm{CNT}_{3} / \mathrm{ZnO}_{3}$, (e) NR$\mathrm{CNT}_{3} / \mathrm{ZnO}_{5}$, and (f) NR-CNT $/ \mathrm{ZnO}_{7}$ nanocomposites. 


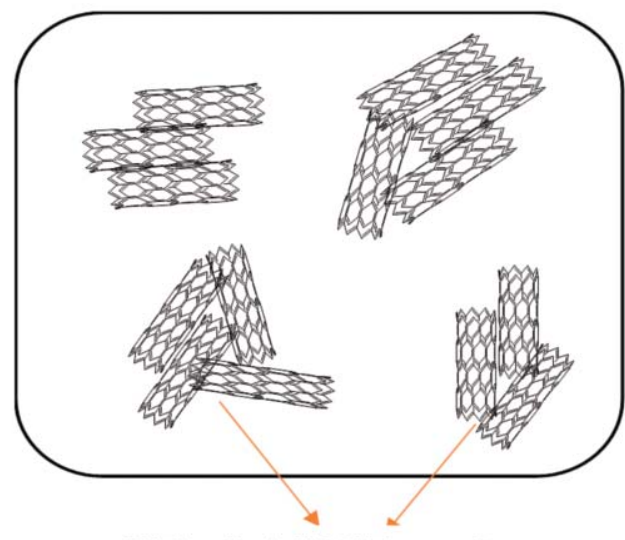

CNT bundles in NR-CNT composite

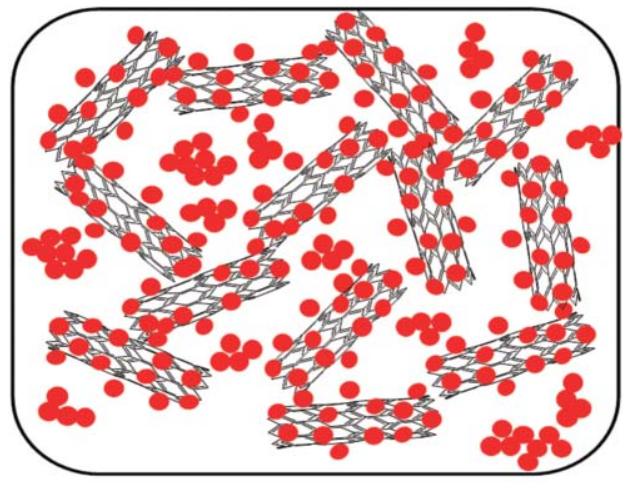

Filler agglomeration in $\mathrm{NR}^{-\mathrm{CNT}_{3}} \mathrm{ZnO}_{3}$
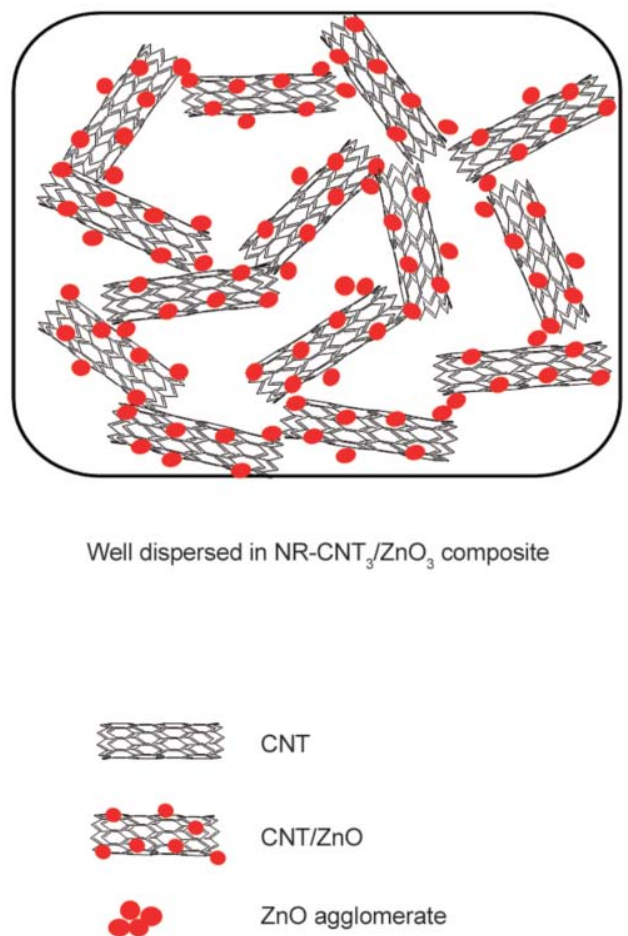

Figure 7. A proposed model for dispersion of $\mathrm{CNT}$ and $\mathrm{CNT} / \mathrm{ZnO}$ hybrid filler in NR matrix.

agglomerates formed in the NR matrix, seen in the FESEM micrographs of Figures $5 \mathrm{~d}$ and $5 \mathrm{~g}$ and the fluorescence stereo micrographs in Figures $6 \mathrm{e}$ and $6 \mathrm{f}$. Thus, it can be concluded that the optimum $\mathrm{ZnO}$ loading in the NR-CNT/ZnO composites is below about 3 phr.

\subsection{Temperature scanning stress relaxation (TSSR) and bound rubber content}

The mechano-thermal relaxation behaviors of the NR gum vulcanizate, NR-CNT, NR-CNT/ZnO hybrid composites were characterized by the TSSR technique, as shown in Figure 8, revealing the dependence of relaxation modulus on temperature for all sample types. Also, the relaxation modulus-temperature curves in the temperature range $23-30^{\circ} \mathrm{C}$ are affected by the entropy effects. Other parts of the relaxation modulus-temperature curve indicate physically bound rubber $\left(30-90^{\circ} \mathrm{C}\right)$, sulfur crosslinks $\left(90-160^{\circ} \mathrm{C}\right)$, and rubber or polymer chain degradation $\left(160-220^{\circ} \mathrm{C}\right)[32]$. In Figure 8a, it is seen that the incorporation of CNT and $\mathrm{CNT} / \mathrm{ZnO}$ hybrid fillers in the NR matrix gave significantly higher initial relaxation modulus than that of the gum NR vulcanizate, which indicates reinforcement effect of the fillers. Furthermore, $\mathrm{CNT} / \mathrm{ZnO}$ hybrid filler with below 3 phr $\mathrm{ZnO}$ content (i.e., $\mathrm{CNT} 3 / \mathrm{ZnO}_{1}$ and $\mathrm{CNT}_{3} / \mathrm{ZnO}_{3}$ ) gave higher initial modulus and curve below $100^{\circ} \mathrm{C}$ temperatures than those of the NRCNT composite. This may be due to the finer dispersion together with more network formation with the CNT-ZnO hybrid fillers, which promote reinforcement of the NR matrix (Figures $5 \mathrm{c}$ and $5 \mathrm{f}$ together with Figures $6 \mathrm{c}$ and $6 \mathrm{~d}$ ). However, with over $3 \mathrm{phr}$ loading of $\mathrm{ZnO}$ in $\mathrm{CNT} / \mathrm{ZnO}$ hybrid filler, strong filler agglomeration occurred (Figures $5 \mathrm{~d}$ and $5 \mathrm{~g}$ as well as Figures $6 \mathrm{~d}$ and $6 \mathrm{f}$ ). Therefore, the relaxation modulus became lesser than that for NR-CNT composite. This relates to the proposed model for the dispersion of CNT and CNT/ZnO hybrid filler in the NR matrix, shown in Figure 7. Also, this was confirmed by the FESEM and fluorescent stereo micrographs in Figures 5 and 6, respectively. Therefore, the $\mathrm{CNT}_{3} / \mathrm{ZnO}_{3}$ has a near-optimal weight ratio of $\mathrm{CNT} / \mathrm{ZnO}$ to create a hybrid filler that bridges networks of $\mathrm{CNT}$ and $\mathrm{ZnO}$ in the NR matrix. In Figure $8 \mathrm{a}$, it is also seen that the relaxation modulus of gum NR is almost constant for $50-130^{\circ} \mathrm{C}$, while the relaxation moduli of NR-CNT and NR-CNT/ZnO clearly decreased with temperature. This was caused 

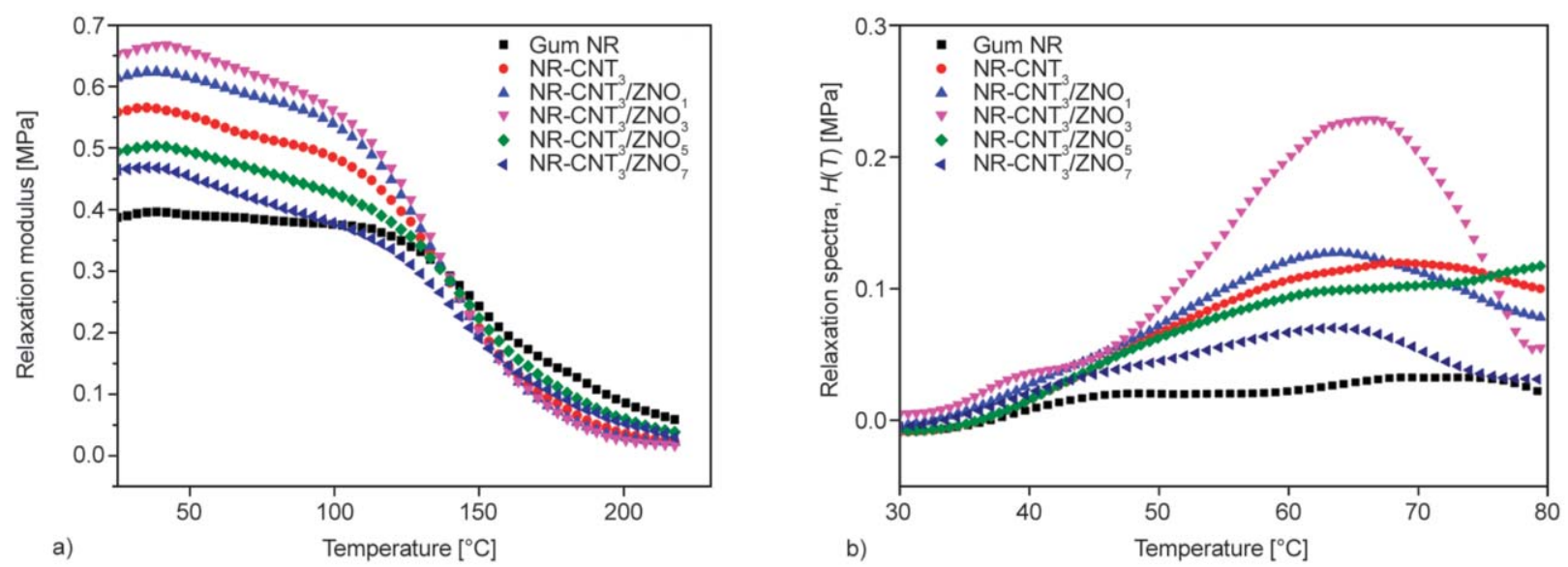

Figure 8. Stress relaxation versus temperature (a), and the relaxation spectra (b) for the gum NR vulcanizate, NR-CNT and different types of NR-CNT/ZnO nanocomposites.

by the physical desorption of bound rubber in the NR-CNT and NR-CNT/ZnO composites, which relaxes the filler-rubber interactions. Furthermore, decreasing moduli are seen in the temperature range from 120 to $220^{\circ} \mathrm{C}$ in all cases. This might be due to thermo-oxidative chain scission of rubber molecules, together with the breakdown of sulfidic crosslinks in the rubber vulcanizates.

The rubber-filler interactions can be assessed from the bound rubber contents in the rubber vulcanizates, which in turn could be estimated from the relaxation spectra $(H(T))$, as shown in Figure $8 \mathrm{~b}$. That is, the relaxation peaks appearing from 50 to $80^{\circ} \mathrm{C}$ indicate desorption of physically bound rubber. It is clear that $\mathrm{CNT}_{3} / \mathrm{ZnO}_{3}$ showed a much larger peak height and peak area than those of the NR-CNT composite. This might be due to the better filler dispersion of $\mathrm{CNT}_{3} /$ $\mathrm{ZnO}_{3}$ than of CNT in the NR matrix. Also, the proper ratio of $\mathrm{CNT}_{3} / \mathrm{ZnO}_{3}$ improved filler dispersion and distribution. This affected the initial relaxation, the large peak height, and peak area, together with the highest bound rubber content in the swelling test, as shown in Figure 9. In Figure 8, it is also seen that the $\mathrm{NR}$ filled with $\mathrm{CNT}_{3} / \mathrm{ZnO}_{1}$ shows lesser initial modulus, peak height, and peak area, and bound rubber content (Figure 9) than the $\mathrm{CNT}_{3} / \mathrm{ZnO}_{3}$ filled NR composite. However, the NR filled with $\mathrm{CNT}_{3} / \mathrm{ZnO}_{1}$ had higher properties than several other cases, including NR-CNT, NR-CNT $/ \mathrm{ZnO}_{5}$, and NR-CNT $3 /$ $\mathrm{ZnO}_{7}$ composites. This corresponds to the fluorescence stereo-micrographs in Figure 6, where the NR$\mathrm{CNT}_{3} / \mathrm{ZnO}_{1}$ composite showed some finely dispersed filler with a small number of aggregates. Nevertheless, CNT-ZnO hybrid filler with higher than $3 \mathrm{phr}$ $\mathrm{ZnO}$ content gave less bound rubber as indicated by

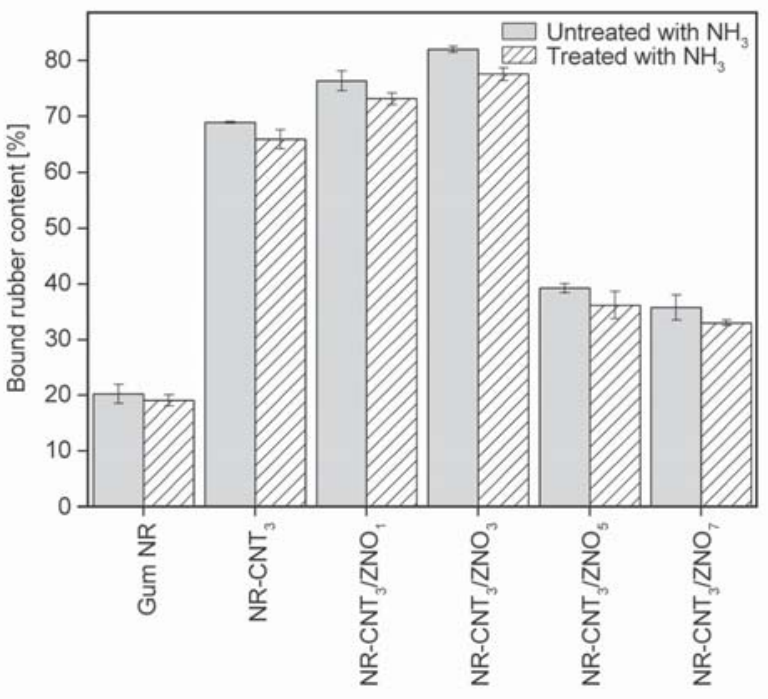

Figure 9. Bound rubber contents determined by swelling method for the gum NR vulcanizate, NR-CNT and different types of NR-CNT/ZnO nanocomposites.

the lower peak height and peak area in the relaxation spectrum $(H(T))$ (Figure $8 \mathrm{~b}$ ) and also by the bound rubber content in Figure 9. This might be due to the $\mathrm{CNT}_{3} / \mathrm{ZnO}_{5}$ and $\mathrm{CNT}_{3} / \mathrm{ZnO}_{7}$ filled NR composites having less physically bound rubber than $\mathrm{CNT}_{3} /$ $\mathrm{ZnO}_{1}$ and $\mathrm{CNT}_{3} / \mathrm{ZnO}_{3}$ and the one with CNT filler.

\subsection{Payne effect}

In order to assess filler networks or filler-filler interactions in the NR composites in terms of strain-induced breakdown, the dynamic properties were examined by plotting storage modulus against a wide range of strains. Figure 10 shows the storage modulus $\left(G^{\prime}\right)$ as a function of strain amplitude for the gum NR vulcanizate, NR-CNT, and different types of NR-CNT/ZnO composites containing various $\mathrm{ZnO}$ fractions in $\mathrm{CNT} / \mathrm{ZnO}$ hybrid filler. Furthermore, 


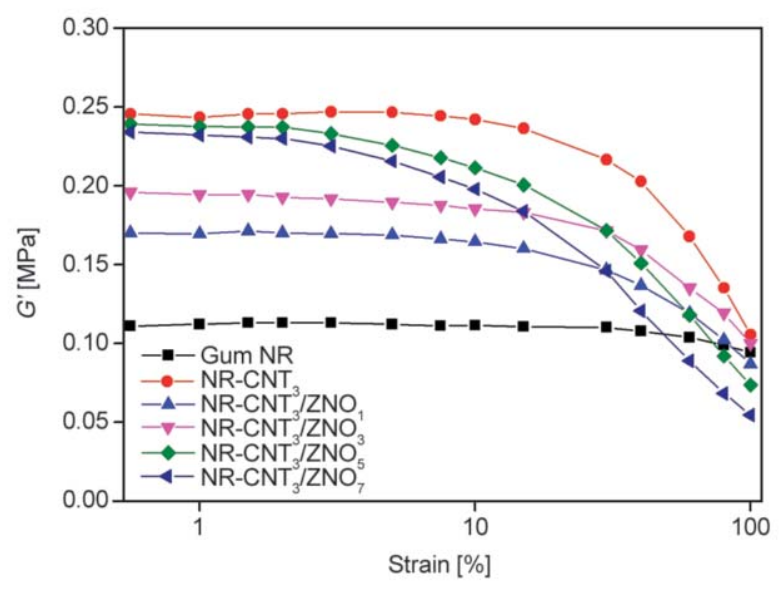

Figure 10. Storage modulus as a function of strain amplitude for the gum NR vulcanizate, NR-CNT and different types of NR-CNT/ZnO nanocomposites.

Table 3 shows storage moduli at the low strain $\left(G_{0.56}^{\prime}\right)$ and the high strain regimes $\left(G^{\prime}{ }_{100}\right)$, as well as storage modulus difference $\left(\Delta G^{\prime}\right)$ for the gum NR vulcanizate and NR-CNT/ZnO composites. In Figure 10 , an almost linear viscoelastic behavior is seen for most strain amplitudes tested, but a slight drop in storage modulus at high strain is seen for the gum NR vulcanizate. This might be due to the disentanglement of natural rubber molecules under the influence of stress. However, large drops in storage moduli are seen with increasing strain amplitude for all the filled NR composites. These are due to the breakdown of filler-filler networks under shear in the dynamic test, known as the Payne effect [33]. It is noted that the level of Payne effect or filler-filler interactions is commonly quantified as the difference between storage moduli at very low strain $\left(G_{0.56}^{\prime}\right)$ and at very high strain $\left(G^{\prime}{ }_{100}\right)$. In this work, the Payne effect is given in terms of $G_{0.56}^{\prime} G^{\prime}{ }_{100}$, indicated by $\left(\Delta G^{\prime}\right)$ in Table 3. A high Payne effect or a strong decrease in storage modulus indicates large filler agglomerates. This is how strong CNT agglomeration in the NR-CNT composites can be demonstrated [34].

Table 3. Storage modulus at very low strain $\left(G_{0.56}^{\prime}\right)$ and at very high strain $\left(G^{\prime}{ }_{100}\right)$, and their difference $\left(\Delta G^{\prime}\right)$ for gum NR un-vulcanizate, NR-CNT and NR$\mathrm{CNT} / \mathrm{ZnO}$ nanocomposites.

\begin{tabular}{|l|c|c|c|}
\hline \multicolumn{1}{|c|}{ Compound } & $\begin{array}{c}\boldsymbol{G}_{\mathbf{0}}^{\prime} \\
{[\mathbf{M P a}]}\end{array}$ & $\begin{array}{c}\boldsymbol{G}_{\mathbf{1 0 0}}^{\prime} \\
{[\mathbf{M P a}]}\end{array}$ & $\begin{array}{c}\Delta \boldsymbol{G}^{\prime} \\
{[\mathbf{M P a}]}\end{array}$ \\
\hline Gum NR & 0.11 & 0.09 & 0.02 \\
\hline $\mathrm{NR}-\mathrm{CNT}_{3}$ & 0.24 & 0.11 & 0.13 \\
\hline $\mathrm{NR}-\mathrm{CNT}_{3} / \mathrm{ZnO}_{1}$ & 0.17 & 0.09 & 0.08 \\
\hline $\mathrm{NR}-\mathrm{CNT}_{3} / \mathrm{ZnO}_{3}$ & 0.19 & 0.10 & 0.09 \\
\hline $\mathrm{NR}_{-}-\mathrm{CNT}_{3} / \mathrm{ZnO}_{5}$ & 0.24 & 0.07 & 0.17 \\
\hline $\mathrm{NR}_{-} \mathrm{CNT}_{3} / \mathrm{ZnO}_{7}$ & 0.23 & 0.05 & 0.18 \\
\hline
\end{tabular}

Furthermore, the lowest Payne effect or the least filler-filler interactions were observed for NR$\mathrm{CNT}_{3} / \mathrm{ZnO}_{1}\left(\Delta G^{\prime}=0.08\right)$ and NR-CNT ${ }_{3} / \mathrm{ZnO}_{3}\left(\Delta G^{\prime}=\right.$ $0.09)$ composites. They have smaller drops in storage moduli with strain amplitude in Figure 10. The NR-CNT composite had a larger Payne effect $\left(\Delta G^{\prime}=\right.$ 0.13 ) with a larger drop of modulus (Figure 10) in comparison to these cases. The larger Payne effect of CNT filled natural rubber relates to strong filler networks from filler-filler interactions [35]. Moreover, the nanocomposites with $\mathrm{CNT} / \mathrm{ZnO}$ hybrid filler having over $3 \mathrm{phr}$ of $\mathrm{ZnO}$, namely NR-CNT $3 / \mathrm{ZnO}_{5}$ $\left(\Delta G^{\prime}=0.17\right)$ and $\mathrm{NR}-\mathrm{CNT}_{3} / \mathrm{ZnO}_{7}\left(\Delta G^{\prime}=0.18\right)$, showed larger Payne effects than the NR-CNT composite, indicating stronger filler-filler interactions with over $3 \mathrm{phr} \mathrm{ZnO}$ content. Therefore, a higher Payne effect was observed in NR-CNT and NR-CNT/ZnO composites with higher loading levels of $\mathrm{ZnO}$ in $\mathrm{CNT} / \mathrm{ZnO}$ than $3 \mathrm{phr}$. This might be attributed to the $\mathrm{ZnO}$ at $3 \mathrm{phr}$ in the $\mathrm{CNT} / \mathrm{ZnO}$ hybrid filler being a proper ratio giving finer filler dispersion with stronger filler-rubber networks in the NR matrix. This also leads to lesser filler-filler interactions but stronger filler-polymer attractions, promoting dispersion and distribution of CNT/ZnO hybrid filler in the NR matrix. However, with $\mathrm{ZnO}$ contents over $3 \mathrm{phr}$, a greater Payne effect was found. This might be due to stronger $\mathrm{ZnO}$ and $\mathrm{CNT}$ agglomerates contributing to stronger average filler-filler interactions or Payne effect. Therefore, the dispersion of $\mathrm{CNT}$ and $\mathrm{ZnO}$ hybrid filler in the NR matrix was significantly enhanced in the NR$\mathrm{CNT}_{3} / \mathrm{ZnO}_{3}$ case, achieving larger values in relaxation spectrum (Figure 8), larger bound rubber content (Figures 8 and 9) and lesser Payne effect (Figure 10) than the other composites tested.

\subsection{Electrical conductivity}

The electrical properties of the NR vulcanizates were examined to confirm the formation of filler pathways with CNT-to-CNT, ZnO-to-ZnO, and CNT-to-ZnO connections, to enable electric currents in the NR matrix. Figure 11 shows electrical conductivity as a function of frequency for the gum NR vulcanizate, NR-CNT, and the various types of NR-CNT/ZnO composites. It can be seen that electrical conductivity linearly increased with frequency and that CNT filler strongly increased electrical conductivity from that of the NR gum vulcanizate. Moreover, a further increase in electrical conductivity was observed after the incorporation of various types of $\mathrm{CNT} / \mathrm{ZnO}$ hybrid 


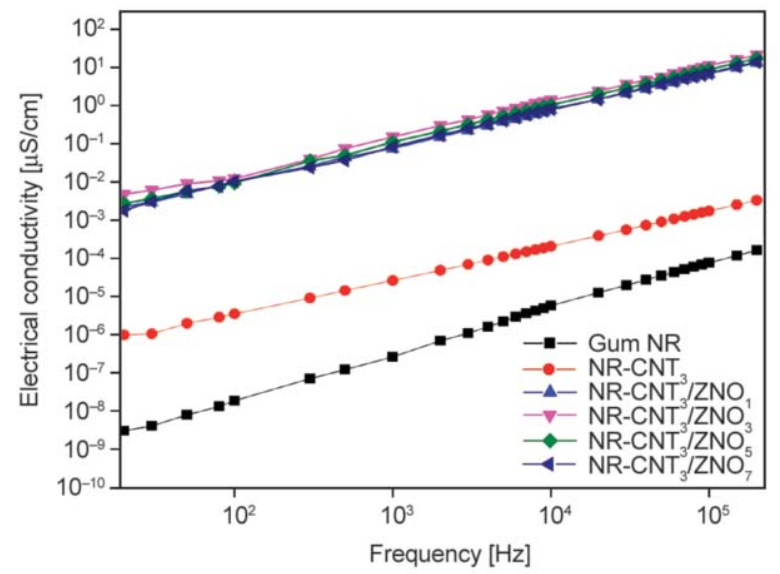

Figure 11. Electrical conductivity as a function of frequency for the gum NR vulcanizate, NR-CNT and different types of NR-CNT/ZnO nanocomposites.

filler, and the highest electrical conductivity at a given frequency was for the NR-CNT $/ \mathrm{ZnO}_{3}$ composite. This might be a synergistic effect of intrinsic high electrical conductivities of $\mathrm{CNT}$ and $\mathrm{ZnO}$, forming filler networks that enable the movement of electrons throughout the rubber matrix. In addition, the electrical conductivity of NR-CNT/ZnO nanocomposites is clearly higher for the composite with finer filler dispersion and distribution, i.e., NR-CNT $\mathrm{CN}_{3} / \mathrm{ZnO}_{3}$ (Figures 5-7) with high bound rubber content (Figures 8 and 9). Due to that, pathways of CNT and $\mathrm{ZnO}$ were formed, connecting electric currents throughout the NR matrix, as demonstrated in Figure 7.

In order to evaluate the critical $\mathrm{ZnO}$ content in $\mathrm{CNT} / \mathrm{ZnO}$ hybrid filler that is optimal for formation of an infinite conductive network in the NR matrix, percolation theory was applied [36]. That is, the optimal conductivity $\left(\omega_{\max }\right)$ observed at a critical filler concentration in the rubber matrix was recognized as the percolation threshold concentration $\left(\varphi_{\mathrm{c}}\right)$ [37]. Figure 12 shows the relationship of the electrical conductivity of the NR-CNT/ZnO hybrid composite with various $\mathrm{ZnO}$ content in the $\mathrm{CNT} / \mathrm{ZnO}$ hybrid filler. Also, the electrical conductivities of gum NR vulcanizate and NR-CNT composite are included in Figure 12 for comparison. It is confirmed that the NR-CNT/ZnO hybrid composites had higher conductivity than did the gum NR vulcanizate and the NR-CNT composite (Figure 11). Additionally, a sudden increase in the electrical conductivity was observed with $1 \mathrm{phr}$ loading of $\mathrm{ZnO}$. Furthermore, increasing the $\mathrm{ZnO}$ content in $\mathrm{CNT} / \mathrm{ZnO}$ hybrid filler to $3 \mathrm{phr}$ caused a marginal increase in the electrical conductivity. However, on increasing $\mathrm{ZnO}$ content

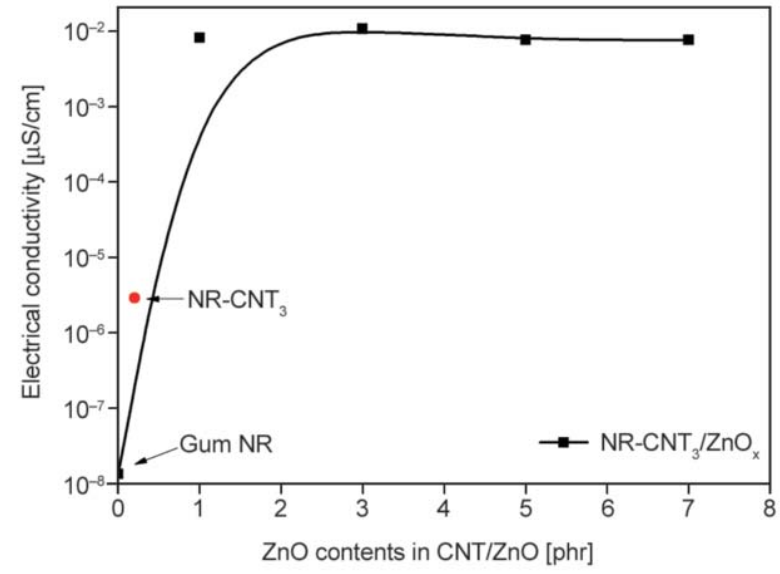

Figure 12. Electrical conductivity of NR-CNT vulcanizate and NR-CNT/ZnO nanocomposites with different $\mathrm{ZnO}$ loadings in $\mathrm{CNT} / \mathrm{ZnO}$ hybrid filler.

in CNT-ZnO beyond $3 \mathrm{phr}$, electrical conductivity remained almost constant. This indicates the formation of infinite conductive filler networks in NR matrix after the addition of $1 \mathrm{phr} \mathrm{ZnO}$ into the CNT$\mathrm{ZnO}$ hybrid composite. This allows the free movement of electrons throughout the rubber matrix. It is noted that the maximum gradient of the curve is taken as the percolation threshold concentration, which is as low as $0.25 \mathrm{phr}$ of $\mathrm{ZnO}$ in this case. This confirms that the CNT/ZnO hybrid filler improved the electrical conductivity of NR from solely CNT filled NR-CNT composite.

Dielectric constant of a material is defined as the ratio of electric permeability of the material and electric permeability of free space (i.e., vacuum), and it can be measured by appeal to a simplified capacitor model [38]. Figure 13 shows the dielectric constants of the NR-CNT and the NR-CNT/ZnO hybrid composites as functions of frequency. Clearly, the gum NR vulcanizate had a frequency-independent dielectric constant. However, all the composites had a slightly decreasing dielectric constant. This may be due to the orientation polarization of polar functional groups in the composites, which becomes more difficult as frequency increases. Furthermore, CNT filler increased the dielectric constant from that of the gum NR vulcanizate. The abrupt increase in the dielectric constant was observed from the incorporation of the $\mathrm{CNT} / \mathrm{ZnO}$ hybrid fillers, due to the conductive nature of CNT and the finer filler networks of CNT and $\mathrm{ZnO}$. Therefore, the NR-CNT/ZnO was able to hold more electric charges for long periods of time, and/or to hold comparatively large quantities of charge. This might be attributed to the charges that can easily move via 


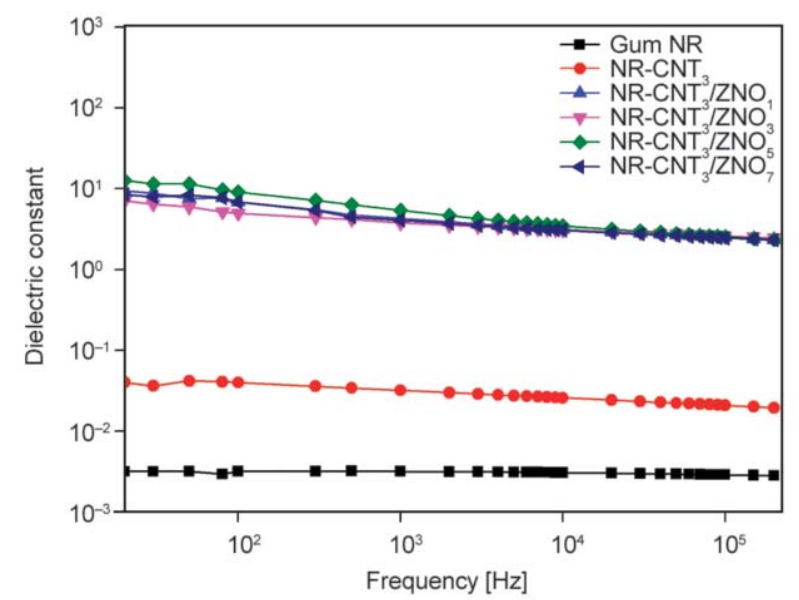

Figure 13. Dielectric constant as a function of frequency for NR-CNT and various types of NR-CNT/ZnO nanocomposites with different $\mathrm{ZnO}$ loadings in $\mathrm{CNT} / \mathrm{ZnO}$ hybrid filler.

the filler pathways and propagate in the NR matrix, to increase conductivity with a high total surface charge reorientation in the surface of $\mathrm{CNT} / \mathrm{ZnO}$ hybrid filler networks. This can be explained by the formation of bridges between $\mathrm{CNT}$ and $\mathrm{ZnO}$ particles, which increased the remaining electron charges collected at the end of a CNT. Therefore, the electron charges in NR-CNT/ZnO hybrid composites can easily flow throughout the NR matrix due to significantly more bound rubber (Figures 8 and 9), higher electrical conductivity (Figure 11) and dielectric constant (Figure 13), but very low percolation threshold concentration (Figure 12). Furthermore, it is noted that superior electrical conductivity, together with high dielectric constant, was found in NR-CNT/ZnO hybrid composites. This could enable making smart materials, for example, for actuators, where high conductivity and high dielectric properties are needed.

\subsection{Dynamic mechanical analysis}

Figure 14 shows the storage modulus $\left(G^{\prime}\right)$ and the loss tangent $(\tan \delta)$ as functions of temperature for gum NR vulcanizate together with NR-CNT, and

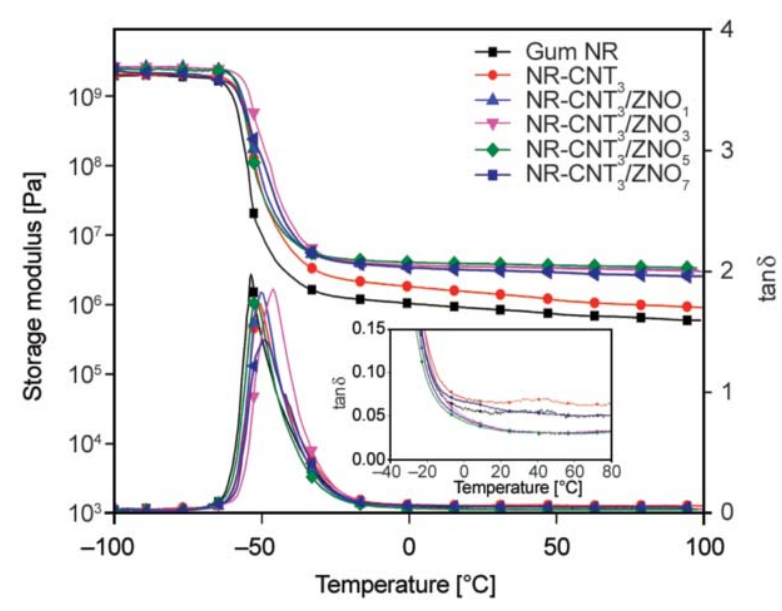

Figure 14. Storage modulus and $\tan \delta$ as functions of temperature for gum NR vulcanizate, NR-CNT and different types of NR-CNT/ZnO nanocomposites.

NR-CNT/ZnO composites. Also, Table 4 shows the glass transition temperatures $\left(T_{\mathrm{g}}\right), \tan \delta_{60}$, and $\tan \delta_{\max }$ for the materials tested in Figure 14. The NR-CNT and NR-CNT/ZnO composites gave larger storage moduli in the glassy region (glass transition) and rubbery region than the gum NR vulcanizate. This is attributed to polymer-filler and filler-filler interactions together with hydrodynamic effects of the fillers (i.e., CNT and CNT-ZnO hybrid). Also, the formation of CNT and $\mathrm{ZnO}$ networks in the NR matrix might be another reason for the higher storage moduli. Furthermore, immediate drops in storage moduli are seen in all samples at the glass transition region, from which the maximum point of decreasing gradient indicates the glass transition temperature $\left(T_{\mathrm{g}}\right)$. This could also be identified at the peak location in the $\tan \delta$ curve. In Figure 14, it can be seen that single $T_{\mathrm{g}}$ are seen for all the samples tested, and these are listed in Table 4. It is clear that the $T_{\mathrm{g}} \mathrm{s}$ of NR-CNT composite and NR-CNT/ZnO hybrid composites are shifted towards higher temperatures from that of the gum NR vulcanizate. This might indicate that the CNT and CNT-ZnO networks in the NR matrix restricted NR chain mobility.

Table 4. Glass transition temperature $\left(T_{\mathrm{g}}\right), \tan \delta_{60^{\circ} \mathrm{C}}, \tan \delta_{\max }$ and crosslink density based on TSSR tests for gum NR vulcanizate together with NR-CNT and different types of NR-CNT/ZnO nanocomposites.

\begin{tabular}{|c|c|c|c|c|}
\hline Compounds & $\begin{array}{c}T_{\mathrm{g}} \\
{\left[{ }^{\circ} \mathbf{C}\right]}\end{array}$ & $\tan \delta_{60}{ }^{\circ} \mathrm{C}$ & $\tan \delta_{\max \left[{ }^{\circ} \mathrm{C}\right]}$ & $\begin{array}{c}\text { Crosslink density } \\
{\left[\mathrm{mol} / \mathrm{m}^{3}\right]}\end{array}$ \\
\hline Gum NR & -55.72 & 0.05 & 1.98 & 68.25 \\
\hline NR-CNT 3 & -50.43 & 0.06 & 1.73 & 84.14 \\
\hline $\mathrm{NR}-\mathrm{CNT}_{3} / \mathrm{ZnO}_{1}$ & -49.17 & 0.03 & 1.83 & 96.56 \\
\hline NR-CNT $3 / \mathrm{ZnO}_{3}$ & -46.24 & 0.03 & 1.86 & 113.84 \\
\hline NR-CNT3/ZnO & -49.84 & 0.03 & 1.77 & 73.22 \\
\hline NR-CNT3/ZnO & -48.80 & 0.05 & 1.44 & 67.58 \\
\hline
\end{tabular}


In Table 4 , it is seen that increased loading of $\mathrm{ZnO}$ in CNT/ZnO composite induced an increase in $T_{\mathrm{g}}$ until $3 \mathrm{phr} \mathrm{ZnO}$ level, where the highest $T_{\mathrm{g}}$ occurred. Increasing the loading of $\mathrm{ZnO}$ past $3 \mathrm{phr}$ decreased $T_{\mathrm{g}}$. This can be explained in terms of good filler-filler interactions favoring the formation of $\mathrm{CNT} / \mathrm{ZnO}$ networks, creating strong interactions between the filler particles and the polymer matrix. Thus, the NR molecular mobility or flexibility was restricted by the formed $\mathrm{CNT} / \mathrm{ZnO}$ networks, and hence the highest $T_{\mathrm{g}}$ was found in the $\mathrm{CNT} / \mathrm{ZnO}$ composite containing $3 \mathrm{phr}$ of $\mathrm{ZnO}$. However, $\mathrm{ZnO}$ at more than $3 \mathrm{phr}$ gave a lower $T_{\mathrm{g}}$. This might be because stronger $\mathrm{ZnO}$ agglomeration increased the free volume in the NR matrix that enabled the NR molecular chains to move freely [39]. Also, the glass transition temperature $\left(T_{\mathrm{g}}\right)$ related to the crosslink density of materials, as shown in Table 4. In this work, the apparent crosslink density was estimated from the maximum slopes at the initial parts of the relaxation modulus-temperature curves in Figure 8a, by applying Equations (6) and (7) $[19,40]$ :

$v_{\mathrm{e}}=\frac{k}{R\left(\lambda-\lambda^{-2}\right)}$

$v_{\mathrm{e}}=\frac{\rho}{M_{\mathrm{c}}}$

where $v_{\mathrm{e}}$ is the apparent crosslink density $\left[\mathrm{mol} / \mathrm{m}^{3}\right]$, $R$ is the universal gas constant, $k$ is the nominal strain ratio, $k$ is the temperature coefficient of stress (the derivative of mechanical stress with respect to temperature), $\rho$ is the mass density, and $M_{\mathrm{c}}$ is defined as the average molar mass of the elastically active network chains, respectively.

In Table 4, it is confirmed that the highest $T_{\mathrm{g}}$ was found in the $\mathrm{CNT} / \mathrm{ZnO}$ composite containing $3 \mathrm{phr}$ of $\mathrm{ZnO}$ (i.e., $\mathrm{NR}-\mathrm{CNT}_{3} / \mathrm{ZnO}_{3}$ ) with the highest crosslink density. Also, the NR-CNT/ZnO with $\mathrm{ZnO}$ at more than $3 \mathrm{phr}$ gave a lower $T_{\mathrm{g}}$. This matches well the $\tan \delta_{\max }$ in Table 4 where the gum NR gave the highest $\tan \delta_{\max }$ while incorporating CNT or CNT/ $\mathrm{ZnO}$ caused reduced $\tan \delta$ max. This indicates that the NR-CNT and NR/CNT-ZnO vulcanizates had less damping than did the gum NR vulcanizates.

Besides, the $\tan \delta$ at $60^{\circ} \mathrm{C}$ is also depicted in Table 4 . It is an important index for high-performance rubber associated with rolling resistance [41]. It can be seen that the NR-CNT composites exhibited higher $\tan \delta$ at $60^{\circ} \mathrm{C}$ than does the gum NR vulcanizate. However, incorporation of $\mathrm{CNT} / \mathrm{ZnO}$ hybrid fillers tended to decrease $\tan \delta$ at $60^{\circ} \mathrm{C}$. This suggests decreased rolling resistance, energy conservation, and environmental benefits from these hybrid composite materials.

\subsection{Mechanical properties}

The tensile properties of gum NR, NR-CNT, and NR$\mathrm{CNT} / \mathrm{ZnO}$ were investigated, and the stress-strain behaviors are shown in Figure 15. It is seen that Young's modulus (initial slope), 100\% modulus, and tensile strength were higher for NR-CNT, NR-CNT ${ }_{3} /$ $\mathrm{ZnO}_{1}$, and NR-CNT $/ \mathrm{ZnO}_{3}$ composites than for the gum NR vulcanizate. This is due to the reinforcing efficiencies of CNT and NR-CNT/ZnO hybrid fillers with $\mathrm{ZnO}$ contents of 1 and $3 \mathrm{phr}$. Furthermore, increasing the loading level of $\mathrm{ZnO}$ in $\mathrm{CNT} / \mathrm{ZnO}$ hybrid filler increased Young's modulus, 100\% modulus, and tensile strength until $3 \mathrm{phr} \mathrm{ZnO}$ loading, where the highest value is seen. Incorporation of more than 3 phr of $\mathrm{ZnO}$ in CNT/ZnO decreased these properties. This is attributed to the formation of $\mathrm{CNT} /$ $\mathrm{ZnO}$ networks with strong interactions between the filler particles and the polymer matrix, particularly at $3 \mathrm{phr} \mathrm{ZnO}$ loading. Whilst higher $\mathrm{ZnO}$ loading in $\mathrm{CNT} / \mathrm{ZnO}$ hybrid filler caused excess $\mathrm{ZnO}$ nanoparticles in the system. Therefore, strong and large $\mathrm{ZnO}$ agglomerates were formed in combination to the free micro- $\mathrm{ZnO}$ activator in NR matrix, which caused decreasing of Young's modulus, 100\% modulus, and tensile strength (Figure 15). This matches well the filler dispersion (Figures 5 and 6), relaxation modulus (Figure 8), and bound rubber content (Figures 8 and 9). Furthermore, lesser elongations at break are seen for NR-CNT and NR-CNT/ZnO composites than for

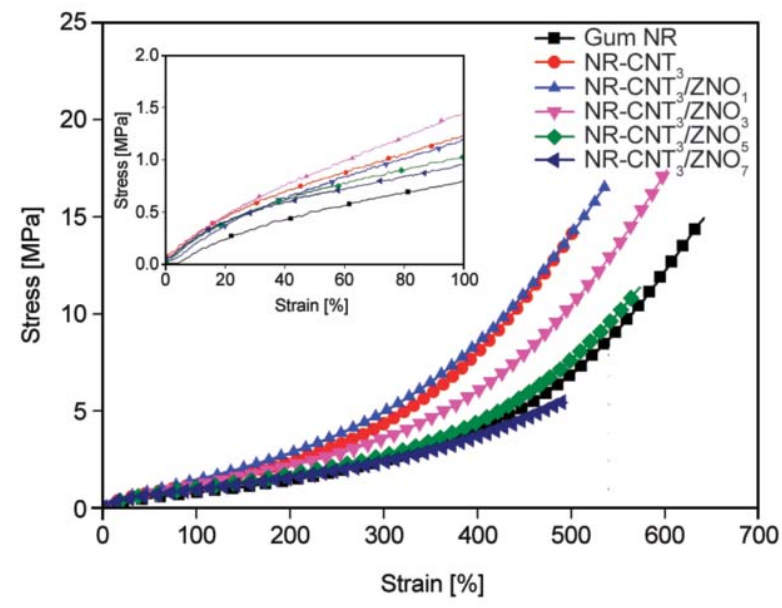

Figure 15. Stress-train curves of the gum NR vulcanizate, NR-CNT and different types of NR-CNT/ZnO nanocomposites. 
the NR vulcanizate. The reduction of extension ability of the composites could be due to the rigid natures of CNT and CNT-ZnO hybrid fillers.

\section{Conclusions}

$\mathrm{ZnO}$ nanoparticles were successfully decorated on CNT surfaces to form a hybrid filler that eagerly networked in an NR matrix. The interactions between carbonyl and hydroxyl groups on CNT surfaces and $\mathrm{Zn}$ ions were observed in FTIR peaks of the functional groups of CNT and $\mathrm{ZnO}$, and in TEM micrographs. The CNT/ZnO hybrid filler at low contents of $\mathrm{ZnO}$ from 1 to $3 \mathrm{phr}$ improved key properties of the NR-CNT/ZnO composites, namely initial stress, bound rubber content, storage modulus, electrical conductivity, and dielectric properties. The finer dispersion and distribution of $\mathrm{CNT}$ and $\mathrm{ZnO}$ fillers in the NR matrix with $\mathrm{CNT} / \mathrm{ZnO}$ network formation and stronger filler-rubber interactions induced the mentioned properties. The dispersion of the fillers was clearly visualized by FESEM and fluorescence stereomicrographs, indicating finer filler dispersion in NR-CNT ${ }_{3} / \mathrm{ZnO}_{3}$ than in NR-CNT composite. Increased bound rubber along with $T_{\mathrm{g}}$ shift to a higher temperature, were observed for the NR-CNT $3 / \mathrm{ZnO}_{3}$ composite.

\section{Acknowledgements}

This work was supported by the Thailand Research Fund under the Distinguished Research Professor Grant no. DPG6080001 and Prince of Songkla University, Surat Thani campus. In addition, Faculty of Science and Industrial Technology, Prince of Songkla University Surat Thani campus are highly acknowledged for research facilities and analytical equipment. English language proofing by Assoc. Prof. Dr. Seppo Karrila is also acknowledged.

\section{References}

[1] Nakaramontri Y., Nakason C., Kummerlöwe C., Vennemann N.: Influence of modified natural rubber on properties of natural rubber-carbon nanotube composites. Rubber Chemistry and Technology, 88, 199-218 (2015).

https://doi.org/10.5254/rct.14.85949

[2] Sharika T., Abraham J., Arif M., George S. C., Kalarikkal N., Thomas S.: Excellent electromagnetic shield derived from MWCNT reinforced NR/PP blend nanocomposites with tailored microstructural properties. Composites Part B: Engineering, 173, 106798/1-106798/13 (2019). https://doi.org/10.1016/j.compositesb.2019.05.009
[3] Grossiord N., Loos J., Regev O., Koning C. E.: Toolbox for dispersing carbon nanotubes into polymers to get conductive nanocomposites. Chemistry of Materials, 18, 1089-1099 (2006). https://doi.org/10.1021/cm051881h

[4] Jose T., Moni G., Salini S., Raju A. J., George J. J., George S. C.: Multifunctional multi-walled carbon nanotube reinforced natural rubber nanocomposites. Industrial Crops and Products, 105, 63-73 (2017). https://doi.org/10.1016/j.indcrop.2017.04.047

[5] Krainoi A., Kummerlöwe C., Nakaramontri Y., Wisunthorn S., Vennemann N., Pichaiyut S., Kiatkamjornwong S. Nakason C.: Influence of carbon nanotube and ionic liquid on properties of natural rubber nanocomposites. Express Polymer Letters, 13, 327-348 (2019). https://doi.org/10.3144/expresspolymlett.2019.28

[6] Nakaramontri Y., Kummerlöwe C., Nakason C., Vennemann N.: The effect of surface functionalization of carbon nanotubes on properties of natural rubber/carbon nanotube composites. Polymer Composites, 36, 2113-2122 (2015).

https://doi.org/10.1002/pc.23122

[7] Nakaramontri Y., Pichaiyut S., Wisunthorn S., Nakason C.: Hybrid carbon nanotubes and conductive carbon black in natural rubber composites to enhance electrical conductivity by reducing gaps separating carbon nanotube encapsulates. European Polymer Journal, 90, 467-484 (2017).

https://doi.org/10.1016/j.eurpolymj.2017.03.029

[8] Guo H., Jerrams S., Xu Z., Zhou Y., Jiang L., Zhang L., Liu L., Wen S.: Enhanced fatigue and durability of carbon black/natural rubber composites reinforced with graphene oxide and carbon nanotubes. Engineering Fracture Mechanics, 223, 106764/1-106764/12 (2020).

https://doi.org/10.1016/j.engfracmech.2019.106764

[9] Krainoi A., Kummerlöwe C., Nakaramontri Y., Wisunthorn S., Vennemann N., Pichaiyut S., Kiatkamjornwong S., Nakason C.: Novel natural rubber composites based on silver nanoparticles and carbon nanotubes hybrid filler. Polymer Composites, 41, 443-458 (2020). https://doi.org/10.1002/pc.25378

[10] Panampilly B., Thomas S.: Nano ZnO as cure activator and reinforcing filler in natural rubber. Polymer Engineering and Science, 53, 1337-1346 (2013). https://doi.org/10.1002/pen.23383

[11] Padmavathy N., Vijayaraghavan R.: Enhanced bioactivity of $\mathrm{ZnO}$ nanoparticles - An antimicrobial study. Science and Technology of Advanced Materials, 9, 035004/1-035004/8 (2008). https://doi.org/10.1088/1468-6996/9/3/035004

[12] Fan Z., Lu J. G.: Zinc oxide nanostructures: Synthesis and properties. Journal of Nanoscience and Nanotechnology, 5, 1561-1573 (2005). https://doi.org/10.1166/jnn.2005.182 
[13] Largani S. H., Pasha M. A.: The effect of concentration ratio and type of functional group on synthesis of $\mathrm{CNT}-$ $\mathrm{ZnO}$ hybrid nanomaterial by an in situ sol-gel process. International Nano Letters, 7, 25-33 (2017). https://doi.org/10.1007/s40089-016-0197-4

[14] Kołodziejczak-Radzimska A., Markiewicz E., Jesionowski T.: Structural characterisation of $\mathrm{ZnO}$ particles obtained by the emulsion precipitation method. Journal of Nanomaterials, 2012, 656353/1-656353/9 (2012). https://doi.org/10.1155/2012/656353

[15] Akhavan O., Azimirad R., Safa S.: Functionalized carbon nanotubes in $\mathrm{ZnO}$ thin films for photoinactivation of bacteria. Materials Chemistry and Physics, 130, 598602 (2011). https://doi.org/10.1016/j.matchemphys.2011.07.030

[16] Li H., Liu Z., Yang S., Zhao Y., Feng Y., Bakenov Z., Zhang C., Yin F.: Facile synthesis of $\mathrm{ZnO}$ nanoparticles on nitrogen-doped carbon nanotubes as high-performance anode material for lithium-ion batteries. Materials, 10, 1102/1-1102/10 (2017). https://oi.org/10.3390/ma10101102

[17] Upasani P., Sreekumar T. V., Gaikar V. G., Jha N.: Preparation of $\mathrm{ZnO} / \mathrm{MWCNT} / \mathrm{PP}$ composite film and its application as multifunctional protective film. Polymer Composites, 39, 157-170 (2018).

https://doi.org/10.1002/pc.23916

[18] Chaudhary D., Singh S., Vankar V. D., Khare N.: ZnO nanoparticles decorated multi-walled carbon nanotubes for enhanced photocatalytic and photoelectrochemical water splitting. Journal of Photochemistry and Photobiology A: Chemistry, 351, 154-161 (2018). https://doi.org/10.1016/j.jphotochem.2017.10.018

[19] Vennemann N., Bökamp K., Bröker D.: Crosslink density of peroxide cured TPV. Macromolecular Symposia, 245-246, 641-650 (2006).

https://doi.org/10.1002/masy.200651391

[20] Wolff S., Wang M-J., Tan E-H.: Filler-elastomer interactions. Part VII. Study on bound rubber. Rubber Chemistry and Technology, 66, 163-177 (1993). https://doi.org/10.5254/1.3538304

[21] Guggilla P., Batra A. K., Edwards M. E.: Electrical characterization of $\mathrm{LiTaO}_{3}: \mathrm{P}(\mathrm{VDF}-\mathrm{TrFE})$ composites. Journal of Materials Science, 44, 5469-5474 (2007). https://doi.org/10.1007/s10853-009-3753-8

[22] Samadi M., Shivaee H. A., Zanetti M., Pourjavadi A., Moshfegh A.: Visible light photocatalytic activity of novel MWCNT-doped ZnO electrospun nanofibers. Journal of Molecular Catalysis A: Chemical, 359, 4248 (2012). https://doi.org/10.1016/j.molcata.2012.03.019

[23] Kumar S., Chaudhary D., Dhawan P. K., Yadav R. R., Khare N.: $\mathrm{Bi}_{2} \mathrm{Te}_{3}$-MWCNT nanocomposite: An efficient thermoelectric material. Ceramic International, 43, 14976-14982 (2017). https://doi.org/10.1016/j.ceramint.2017.08.017
[24] Zhu L-P., Liao G-H., Huang W-Y., Ma L-L., Yan Y., Yu Y., Fu S-Y.: Preparation, characterization and photocatalytic properties of $\mathrm{ZnO}$-coated multi-walled carbon nanotubes. Materials Science and Engineering: B, 163, 194-198 (2009). https://doi.org/10.1016/j.mseb.2009.05.021

[25] Yu Y., Huang W-Y., Li J-L., Ma L-L.: Preparation and photocatalytic property of ZnO/MWCNTs composites. in 'Solid state chemistry research trends' (ed.: Buckley R. W.) Nova Science, New York, 1-22 (2007).

[26] Yu Y., Ma L-L., Huang W-Y., Li J-L., Wong P-K., Yu J. C.: Coating MWNTs with $\mathrm{Cu} 2 \mathrm{O}$ of different morphology by a polyol process. Journal of Solid State Chemistry, 178, 1488-1494 (2005).

https://doi.org/10.1016/j.jssc.2005.02.016

[27] Jia B., Gao L., Sun J.: Self-assembly of magnetite beads along multiwalled carbon nanotubes via a simple hydrothermal process. Carbon, 45, 1476-1481 (2007). https://doi.org/10.1016/j.carbon.2007.03.025

[28] Junkong P., Cornish K., Ikeda Y.: Characteristics of mechanical properties of sulphur cross-linked guayule and dandelion natural rubbers. The Royal Society of Chemistry, 7, 50739-50752 (2017).

https://doi.org/10.1039/C7RA08554K

[29] Wang L., Qi T., Hu M., Zhang S., Xu P., Qi D., Wu S., Xiao H.: Inhibiting mercury re-emission and enhancing magnesia recovery by cobalt-loaded carbon nanotubes in a novel magnesia desulfurization process. Environmental Science and Technology, 51, 11346-11353 (2017).

https://doi.org/10.1021/acs.est.7b03364

[30] Gómez S., Rendtorff N. M., Aglietti E. F., Sakka Y., Suárez G.: Surface modification of multiwall carbon nanotubes by sulfonitric treatment. Applied Surface Science, 379, 264-269 (2016).

https://doi.org/10.1016/j.apsusc.2016.04.065

[31] Coates J.: Interpretation of infrared spectra, A practical approach. in 'Encyclopedia of analytical chemistry' (ed.: Meyers R. A.) Wiley, New York, 10815-10837 (2006). https://doi.org/10.1002/9780470027318.a5606

[32] Vennemann N., Schwarze C., Kummerlöwe C.: Determination of crosslink density and network structure of NR vulcanizates by means of TSSR. Advanced Materials Research, 844, 482-485 (2014). https://doi.org/10.4028/www.scientific.net/AMR.844.482

[33] Payne A. R.: Effect of dispersion on the dynamic properties of filler loaded rubbers. Journal of Applied Polymer Science, 9, 2273-2284 (1965). https://doi.org/10.1002/app.1965.070090619

[34] Subramaniam K., Das A., Stöckelhuber K. W., Heinrich G.: Elastomer composites based on carbon nanotubes and ionic liquid. Rubber Chemistry and Technology, 86, 367-400 (2013).

https://doi.org/10.5254/rct.13.86984 
[35] Fröhlich J., Niedermeier W., Luginsland H-D.: The effect of filler-filler and filler-elastomer interaction on rubber reinforcement. Composites Part A: Applied Science and Manufacturing, 36, 449-460 (2005). https://doi.org/10.1016/j.compositesa.2004.10.004

[36] Bokobza L.: Enhanced electrical and mechanical properties of multiwall carbon nanotube rubber composites. Polymer Advanced and Technology, 23, 1543-1549 (2012).

https://doi.org/10.1002/pat.3027

[37] Bokobza L.: Multiwall carbon nanotube elastomeric composites: A review. Polymer, 48, 4907-4920 (2007). https://doi.org/10.1016/j.polymer.2007.06.046

[38] Brebels J., Manca J. V., Lutsen L., Vanderzande D., Maes W.: High dielectric constant conjugated materials for organic photovoltaics. Journal of Materials Chemistry A, 5, 24037-24050 (2017).

https://doi.org/10.1039/C7TA06808E
[39] Salaeh S., Boiteux G., Cassagnau P., Nakason C.: Flexible 0-3 ceramic-polymer composites of barium titanate and epoxidized natural rubber. International Journal of Applied Ceramic Technology, 12, 106-115 (2015). https://doi.org/10.1111/ijac.12129

[40] Matchawet S., Kaesaman A., Vennemann N., Kumerlöwe C., Nakason C.: Effects of imidazolium ionic liquid on cure characteristics, electrical conductivity and other related properties of epoxidized natural rubber vulcanizates. European Polymer Journal, 87, 344-359 (2017). https://doi.org/10.1016/j.eurpolymj.2016.12.037

[41] Lin Y., Chen Y., Zeng Z., Zhu J., Wei Y., Li F., Liu L.: Effect of $\mathrm{ZnO}$ nanoparticles doped graphene on static and dynamic mechanical properties of natural rubber composites. Composites Part A: Applied Science and Manufacturing, 70, 35-44 (2015).

https://doi.org/10.1016/j.compositesa.2014.12.008 